\title{
Ser migrante en la Barcelona de 1930. La inmigración valenciana en el barrio de la Barceloneta ${ }^{1}$ \\ Being a Migrant in Barcelona in 1930. Valencian Immigration in the Neighbourhood of la Barceloneta
}

\author{
Kenneth Pitarch Calero \\ Centre d'Estudis Demogràfics / CERCA \\ Universitat Autònoma de Barcelona \\ kpitarch@ced.uab.es \\ ORCID: 0000-0003-3874-0381 \\ Conchi Villar Garruta \\ Universitat de Barcelona \\ cvillar@ub.edu \\ ORCID: 0000-0003-1610-1933 \\ Antonio López-Gay \\ Centre d'Estudis Demogràfics / CERCA \\ Universitat Autònoma de Barcelona \\ tlopez@ced.uab.es \\ ORCID: 0000-0001-8892-2816
}

Recibido: 10-5-2018

Aceptado: 11-6-2018

Cómo citar este artículo / Citation: PITARCH CALERO, Kenneth, VILLAR GARRUTA, Conchi, LÓPEZ-GAY, Antonio (2018). Ser migrante en la Barcelona de 1930. La inmigración valenciana en el barrio de la Barceloneta. Pasado y Memoria. Revista de Historia Contemporánea, 17, pp. 259-299. https://doi.org/10.14198/PASADO2018.17.10

\footnotetext{
${ }^{1}$ Este artículo forma parte de la tesis doctoral Anàlisi Sociodemogràfica de la Migració Valenciana a Catalunya i Altres Destinacions realizada por Kenneth Pitarch (kpitarch@ced. uab.es) y dirigida por los doctores Andreu Domingo (adomingo@ced.uab.es) y Amand Blanes (ablanes@ced.uab.es). Una versión preliminar fue presentada en el XII European Social Science History Conference en Belfast en abril de 2018.
} 


\title{
Resumen
}

En 1930, más de la mitad de la población barcelonesa (56\%) había nacido fuera de la ciudad. Diversos estudios han investigado sobre la migración interna, pero no existen estudios específicos sobre el grupo migratorio más importante del momento: el valenciano. El objetivo del presente trabajo es contribuir a mejorar nuestro conocimiento sobre las condiciones de vida y el nivel de integración de este colectivo en la Barcelona de 1930. Para ello, se analiza: (i) la distribución en el espacio urbano de la inmigración valenciana y (ii) las principales características sociodemográficas y el nivel de integración socio-laboral de este grupo en la Barceloneta, determinando el periodo y las razones de su llegada a Barcelona. Los resultados apuntan a una relativa buena integración en la ciudad -comparada con otros grupos migratorios- que no dependía del momento de llegada y que estaría vinculada al mantenimiento de unos fuertes lazos de paisanaje.

Palabras clave: Migración valenciana. Padrón. Barcelona. País Valenciano. Hogares. Ocupaciones. Demografía. Industrialización.

\begin{abstract}
In 1930, more than half of the Barcelona population (56\%) had been born outside the city. Although internal migration of that period has been studied, there is no specific research on its most important origin: the Valencian born migrants. The aim of this work is to improve our knowledge about the living conditions and the level of integration of this group in Barcelona in 1930. For this purpose, we analyze: (i) The distribution of Valencia born migrants in Barcelona. (ii) The main sociodemographic characteristics and the the level of socio-labour integration of this group living in La Barceloneta neighbourhood. This is done by focusing on the timing and the reasons behind their movement to Barcelona. Results point out a relatively good social integration -compared with other migratory groups- that did not depend on the period of arrival. We suggest, however, it is linked to the maintenance of strong ties of peasantry.
\end{abstract}

Keywords: Valencian migration. Municipal Register of Inhabitants. Barcelona. Valencian Country. Households. Occupations. Demography. Industrialization.

\section{Introducción}

Desde finales del siglo XIX, el crecimiento demográfico de Cataluña se ha sustentado en la inmigración (Cabré, 1999) de tal manera que, actualmente, un $70 \%$ de su población es el resultado directo o indirecto de la migración del siglo XX (Domingo, 2012). Sin embargo, mientras la inmigración ha recibido una enorme atención desde de la sociología y la demografía catalanas, contamos todavía con pocos estudios históricos que aborden los determinantes de la inmigración y sus condiciones de vida en Cataluña en el período anterior a la Guerra Civil (1936-1939).

En el ámbito europeo, diversos estudios han abordado la cuestión de la integración socioeconómica y las condiciones de vida de la población inmigrante en contextos urbanos durante el proceso de industrialización. Concretamen- 
te, en el caso del Reino Unido, se ha señalado que la inmigración campo-ciudad durante parte de la época Victoriana, a excepción de la irlandesa, ${ }^{2}$ estuvo positivamente seleccionada (Long, 2005). Incluso estos migrantes encontraron en la ciudad mejores condiciones salariales que los propios nativos y fueron menos proclives a sufrir el desempleo (Willianson, 1990; Hatton y Bailey, 2002). Tampoco en el caso de Amberes, en Bélgica, entre mediados del siglo XIX y el primer tercio del siglo XX, se han observado diferencias significativas entre las condiciones laborales de los nacidos en la ciudad y los migrantes, ni siquiera en el caso de los valones (Puschmann et al., 2014). ${ }^{3}$ En cambio, en Alemania, concretamente en Bremen, la abolición de barreras migratorias provocó -sobre todo a partir de $1860-{ }^{4}$ que los inmigrantes se concentrasen en trabajos informales, mal remunerados y poco cualificados. Pero a partir de finales del siglo XIX, una serie de cambios (sanitarios, industriales, pero también migratorios) provocaron la mejora, incluso por encima de los propios nativos, de las condiciones de vida de la población migrante (Lee y Marschalck, 2000).

En España también contamos con trabajos que han analizado estas cuestiones en diferentes contextos. En el caso de Madrid, similar al de Bremen en su primera etapa, la incorporación masiva de inmigrantes a la actividad económica condujo a una pauperización del mercado laboral y sus condiciones (Pallol el at., 2010). No obstante, a partir del siglo XX se inició un cambio en la inserción laboral de los inmigrantes, fruto de las transformaciones que experimentó el mercado laboral madrileño (Otero y Pallol, 2009; Carballo, 2011). El desarrollo de nuevos oficios en el transporte, las comunicaciones y los negocios, junto con el aumento del funcionariado, trajo consigo un paulatino descenso del hasta entonces mayoritario sector de los jornaleros y una multiplicación de los trabajadores de cuello blanco, los conocidos como empleados (Pallol, 2011). ${ }^{5}$

\footnotetext{
${ }^{2}$ Los irlandeses constituyeron uno de los grupos migrantes más desfavorecidos dentro del Reino Unido, aunque entre ellos construyeron redes de solidaridad muy sólidas basadas en su origen y, sobre todo, en la adscripción a la religión católica (Fielding, 1993; Belchem, 1999).

${ }^{3}$ Los choques entre flamencos y valones se remontan a la misma fundación de Bélgica como nación en 1830, con episodios de discriminación social y económica que han sido frecuentes desde entonces tanto en Flandes como en Valonia (Mnookin, 2007).

${ }^{4}$ En Alemania las migraciones internas de largo recorrido comienzan a cobrar cierta importancia a partir de 1850, hasta entonces la mayoría de movimientos eran locales o de pequeño recorrido (Kocka, 1986).

${ }^{5}$ De esta manera, junto con el grupo de los jornaleros que representaba un $27 \%$ en el sector servicios, los trabajadores de cuello blanco, los profesionales liberales y los pequeños comerciantes alcanzaron un $27 \%$, un $5 \%$ y otro $5 \%$ respectivamente de la mano de obra masculina madrileña (Pallol, 2011: 207).
} 
En Vizcaya, una zona caracterizada por un desarrollo económico ligado a la actividad industrial, la integración de la población migrante en el mercado laboral varió según territorios. Así, en las áreas industriales de la Ría de Bilbao, los inmigrantes se integraron mayoritariamente como jornaleros en las minas o en las nuevas industrias (González et al., 2011). El sector servicios, el artesanal y el agrícola, especialmente este último, quedaron en gran medida reservados a la población nativa (García, 2005: 203), salvo en algunas ciudades, como la capital o los municipios del Abra y Guecho (González et al., 2011).

En el caso de Barcelona, y a diferencia de lo ocurrido en Madrid y Bremen, algunos estudios señalan que a lo largo del primer tercio del siglo XX las posibilidades de integración de la inmigración, al menos la masculina, ${ }^{6}$ se deterioraron (Oyón, 2015; Silvestre et al., 2015) ${ }^{7}$. La elevada demanda de mano de obra poco cualificada, fruto del avance de la mecanización y las obras de construcción de grandes infraestructuras (Tatjer, 1995; Oyón et al. 2001; Arango, 2007) contribuyeron a cambiar el perfil de la inmigración. De esta manera, a partir de la I Guerra Mundial, los colectivos inmigrantes procedentes de Murcia y la Andalucía oriental, aunque también del País Valenciano y Aragón, habrían padecido unas condiciones sociolaborales y de vida peores que sus antecesores. Su integración en el entorno urbano se habría visto dificultada por su extracción rural y el viciado papel que tuvieron las cadenas migratorias. Así, si bien las redes de solidaridad facilitaban en un primer momento el acceso a trabajos poco cualificados, a largo plazo dificultaban el acceso a ocupaciones más cualificadas (Silvestre et al.; 2015: 1011). Además, el proceso de segregación y concentración de la inmigración que se produjo en la ciudad desde principios del siglo XX (Oyón, 2008) habría contribuido a menguar las perspectivas de mejora, al menos en el corto-medio plazo, de la inmigración más reciente.

El objetivo de este artículo es analizar este proceso; contrastar si, efectivamente, la inmigración perdió capacidad de integración en la ciudad, y en qué condiciones se produjo dicho proceso. Nos centramos para ello en la inmigración valenciana, uno de los colectivos de procedencia no catalana que, precisamente porque protagonizó la primera gran oleada de inmigración que reci-

${ }^{6}$ Algunos trabajos sí han constatado que las mujeres inmigrantes han ocupado tradicionalmente los estratos inferiores de la estructura ocupacional catalana y han tenido menos presencia en la industria, concretamente en el sector textil, y en las ramas de menor valor añadido, como el servicio doméstico (Solé 1981; Llonch, 1994; López, 2004).

${ }^{7}$ De hecho, según determinados autores, serían las escasas expectativas de movilidad social del sector inmigrante de la clase obrera en Barcelona lo que explicaría una presencia revolucionaria superior a lo normal (Ealham, 2005; Oyón, 2009; 2015: 20). 
bió Barcelona desde finales del siglo XIX y porque era considerado un colectivo fácil de integrar, al compartir -parte de ellos ${ }^{8}$ una misma lengua (Balcells, 2015), se sitúa como grupo de especial interés para contrastar esta hipótesis.

El presente artículo se estructura en cinco apartados. Tras la introducción, en el primer apartado damos cuenta, muy brevemente, de las fuentes y la metodología utilizadas. El segundo sitúa los orígenes, destinos y causas de la emigración valenciana entre mediados del siglo XIX y el primer tercio del siglo XX. En el tercer apartado, núcleo central de la investigación, analizamos la distribución de la población valenciana en la Barcelona de 1930, así como las causas del enorme crecimiento demográfico que se produjo a principios del siglo XX. A continuación, en la cuarta parte, analizamos las condiciones de vida y el nivel de integración de la inmigración valenciana en el barrio de la Barceloneta, una de las zonas de mayor concentración del colectivo valenciano en la ciudad. Finalmente, se apuntan una serie de ideas finales a modo de conclusión.

\section{Fuentes y metodología}

Para este estudio hemos utilizado dos fuentes principales. La primera es la Tabla Clasificatoria de la Población según Provincia de Nacimiento -o Para los Nacidos en el Extranjero, Países- y Sexo, publicada en la Gaseta Municipal de Barcelona del 6 de junio de 1932 (p. 496 y siguientes). Dicha tabla nos ha permitido situar en el mapa las áreas de mayor concentración y distribución de la población valenciana residente en Barcelona.

La segunda fuente principal de este estudio son las hojas originales del Padrón Municipal de Habitantes de 1930, el primer padrón que se conserva de forma integral para la ciudad de Barcelona. ${ }^{9}$ Los padrones de habitantes son una fuente bien conocida que no requiere de una extensa presentación. En general, recogen datos sociodemográficos sobre los residentes en cada domicilio (sexo, edad, origen, estado civil, nivel de instrucción, ocupación, tiempo

\footnotetext{
${ }^{8}$ Recordemos que no todos los valencianos son, o eran entonces, valencianohablantes. En realidad, de las 34 comarcas en las que está dividido el País Valenciano, 8 son históricamente castellanohablantes (Alto Mijares, Alto Palancia, Serranos, Rincón de Ademuz, Requena-Utiel, Hoya de Buñol, Valle de Cofrentes y Canal de Navarrés) y en otras tantas, históricamente valencianohablantes, también existen municipios castellanohablantes (Beltran y Segura-Llopes, 2017). Así que, excepto los inmigrantes procedentes de estas últimas zonas -por otro lado, muy numerosos en ciertas zonas de Barcelona en 1930 como el Poble-sec o Poblenou (Oyón et al., 2001)- los inmigrantes valencianos, junto con los baleáricos, eran vistos con más proximidad por los catalanes, de manera que incluso algunos partidos políticos catalanistas de la época, como la Lliga Regionalista o ERC, no dudaron en buscar el voto de estos colectivos en sus candidaturas (Balcells, 2015).

${ }^{9}$ Depositado en el Arxiu Municipal Contemporani de Barcelona.
} 
de residencia en la ciudad, parentesco con el cabeza de familia, año de llegada, etcétera) que permiten reconstruir la estructura socioeconómica de un municipio en un momento dado, tanto desde la perspectiva del individuo como desde la perspectiva de los hogares. ${ }^{10}$ En este caso, analizamos los datos individuales de una muestra conformada por el 33\% de los domicilios de los barrios centrales de la Barceloneta -Concòrdia y Orientals- en los que residían, al menos, una persona nacida en el País Valenciano independientemente de su sexo y de su posición dentro del hogar. El área seleccionada es, como veremos a continuación, de las que mayor concentración de inmigración valenciana presenta en la ciudad.

\section{Emigraciones valencianas entre mediados del siglo XIX y el primer tercio del siglo XX: orígenes, destinos y causas}

En el País Valenciano, desde finales del siglo XVIII se registraron frecuentes movimientos inter e intraprovinciales a lo largo de todo el territorio, explicados por el desarrollo agrícola de muchas comarcas (Furió, 2001; Piqueras, 2005) y, sobre todo a partir del XIX, por la expansión industrial (Torró, 1996). Es precisamente en el último cuarto de este siglo cuando los movimientos, esta vez dirigidos al exterior, se intensificaron. Una serie de catástrofes meteorológicas, ${ }^{11}$ un gravísimo brote de cólera en $1885^{12}$ y la denominada Gran Depresión -que se dejó sentir de manera especialmente intensa en las zonas arroceras- sumieron al campo valenciano en una grave crisis económica (Carnero, 1978) que se saldó con un importante movimiento emigratorio. Apenas había empezado a remontarse la situación, la crisis se agravó en los primeros años del siglo XX: la llegada de la filoxera arruinó buena parte de los viñedos (Piqueras, 2005) ${ }^{13}$ y forzó a emigrar a gran parte de los agricultores que habían resistido las crisis producidas en los años finales del siglo anterior. Fuera de la Península,

${ }^{10}$ Para una información más detallada sobre esta fuente, véase Oyón et al. (2001).

${ }^{11}$ En 1878 se sucedieron grandes pérdidas en la huerta valenciana, debido a intensas heladas, y en 1879 y 1885 una serie de inundaciones afectaron a la provincia de Alicante (Mirri, 1994).

${ }^{12}$ Este brote de cólera -uno de los diversos registrados en España en el siglo XIX, especialmente en su mitad oriental- afectó con especial virulencia al País Valenciano, ya que llegó a causar la muerte directa de 33.609 personas (Fernández, 1991).

${ }^{13}$ La filoxera entró en el País Valenciano casi al mismo tiempo por el extremo norte y sur. En 1902 llegó a Benicarló y Vinaròs procedente de Tarragona y al cabo de dos años se extendió hacia el sur por el Maestrat y la Plana de Castellón. Por el sur empezó afectando los escasos viñedos de Dolores, pero no fue hasta 1905 y 1906 cuando se propagó hasta Alicante y Monóvar, desde donde alcanzó Villena en 1909 y Jumilla en 1912 (Piqueras, 2005). 
estos flujos se dirigieron, fundamentalmente, a Argelia (Bonmatí, 1989; Menages y Monjo, 2007) ${ }^{14}$ y Francia (Piqueras y Lungu, 2007), ${ }^{15}$ aunque en Uruguay (Folguerà, 1997; Agulló, 2011), Argentina (Alonso, 2010) y Norteamérica (Morell, 2012; Alapont, 2013; Ortuño, 2013), también llegaron miles de valencianos en estas fechas. Jornaleros y braceros pusieron rumbo a estos países para escapar de la falta de tierras, el paro estacional y las catástrofes climáticas y atraídos por un mercado laboral que, debido a la escasez de mano de obra, ofrecía mejores condiciones laborales.

Dentro de la Península, el principal destino de la emigración valenciana desde que se tienen registros estadísticos ha sido Cataluña (Domingo y Pitarch, 2015). ${ }^{16}$ Desde finales del siglo XIX, contingentes importantes se establecieron en municipios de la costa catalana, atraídos bien por ser centros especializados en determinadas actividades agrícolas, bien por la posibilidad de dedicarse a la actividad maritimopesquera. Así, el Delta del Ebro constituyó un área de atracción de colles (cuadrillas) que emigraban temporalmente para participar en las tareas del arroz (Queralt, 2006). ${ }^{17}$ En Gavà se asentaron agricultores, jornaleros y familias enteras procedentes de Olocau de Carraixet especializados en la recolección del palmito (Campmany, 2015) ${ }^{18}$ y en Sant Jordi d'Alfama -dentro del municipio de la Ametlla de Mar- (Figueres, 2017),

${ }^{14}$ Argelia capitalizó casi en exclusiva los movimientos externos desde la provincia de Alicante. Por ejemplo, para el bienio 1888-1900, casi el 93\% de la emigración externa total de la provincia de Alicante y el 57\% de la de Valencia (Sánchez, 1995).

${ }^{15}$ Francia devino un destino muy atractivo para muchos valencianos, la mayoría castellonenses, desde finales del siglo XIX, aunque fue a partir de la I Guerra Mundial cuando se produjo un punto de inflexión y las salidas se multiplicaron. De hecho, casi 30.000 castellonenses emigraron al país galo durante el conflicto bélico, el 85,5\% de los cuales para dedicarse a la agricultura. Si tenemos en cuenta la población total de Castellón durante este periodo, emigró más del 10\% de la población (Piqueras, 2007).

${ }^{16}$ Madrid fue, junto a Barcelona, otro punto importante de recepción de inmigración interior en España en el primer tercio del siglo (Silvestre, 2007), pero no para el colectivo valenciano. Así, en 1920 en Cataluña había 91.211 valencianos registrados, por 13.990 en la provincia de Madrid. Diez años más tarde, el número de estos últimos aumentó solo hasta los 18.835 (Cortizo, 1983) por los 126.165 de Cataluña.

${ }^{17}$ Diversos estudiosos han relacionado el origen de las barracas del Delta del Ebro con la llegada de familias de origen valenciano para preparar las tierras y ponerlas en cultivo entre finales del siglo XIX y principios del siglo XX (Queralt, 2006).

${ }^{18}$ Un recorrido por la historia de la colonia valenciana de Gavà puede verse en Campmany (2015). Se trata de uno de los pocos trabajos que toma como objeto de estudio el colectivo valenciano en Cataluña exclusivamente. Se centra, por ejemplo, en sus periodos de llegada o su participación en la sociedad de Gavà del momento, en donde crearon, en 1930, una de las casas regionales valencianas más antiguas de toda Cataluña y que actualmente sigue estando en funcionamiento 
Roses (Llorca, 2000) ${ }^{19}$ y Palamós (Alegret y Garrido, 2008) se instalaron pescadores y sus familias en busca de mejores oportunidades.

No obstante, más allá de estos flujos, fue Barcelona y su área más próxima la que atrajo mayor número de población valenciana. Tanto fue así que buena parte de dicha población, al no encontrar vivienda en la capital -al igual que la inmigración catalana, murciana y aragonesa- optó por desplazarse a localidades de la periferia de Barcelona y se integró en el mercado de trabajo local. Sucedió en ciudades como Sabadell o Santa Coloma de Gramanet, que tuvieron que acoger un gran número de migrantes valencianos ya a finales del siglo XIX. En Sabadell, especialmente alcoyanos, que habrían emigrado debido a la dura crisis del textil que tuvo lugar en su zona de origen en los años 50, pero sobre todo en los años 80 del siglo XIX (Egea, 1984). ${ }^{20}$ En Santa Coloma, en cambio, el $82 \%$ de los valencianos procedía de las provincias de Castellón y Valencia (Gallardo y Oyón, 2004).

Los estudios que han analizado la presencia de la inmigración valenciana en Barcelona la dibujan como un colectivo que llegó a la ciudad, mayoritariamente, entre mediados del siglo XIX y principios del XX (Arango, 1976; Pujadas, 1982; Oyón et al., 2001). Sin embargo, a partir de la década de 1920, el número de llegadas procedentes del País Valenciano se fue progresivamente estancando y desde 1930 -cuando alcanzaron el máximo poblacional de todo el siglo con más de 126 mil personas residiendo en el Principado (Domingo y Pitarch, 2015) - no se ha vuelto a recuperar. Como el resto de la inmigración que llegó a la ciudad en ese periodo, la población valenciana habría llegado atraída por la elevada demanda de mano de obra que generó la expansión industrial, la realización de grandes eventos y la construcción de vivienda y obra pública (Tatjer, 1973; Recaño, 1996; Arango, 2007; Silvestre, 2010).

Por lo que concierne a las zonas de asentamiento dentro de la ciudad, sabemos que desde finales del siglo XIX la presencia de población valenciana era muy destacada en el antiguo municipio independiente de Sant Martí de Provençals (Mirri, 1994). A principios del siglo XX, también era notable su presencia en el centro, en el antiguo barrio de Sant Cugat del Rec, cuyo territorio forma parte del actual barrio de Santa Caterina, en Ciutat Vella. Junto a la inmigración catalana y baleárica, la población valenciana formaba parte de

${ }^{19}$ En Roses, por ejemplo, entre 1910 y 1920 el número de pescadores pasó de 178 a más de 400, los cuales venían en su mayor parte de la Ametlla de Mar o de la población alicantina de El Campello (Llorca, 2000).

${ }^{20}$ De hecho, en los años de cambio del siglo XIX al XX, la prensa utilizaba la palabra alcoyano - una comunidad de relativa consideración- para designar a los grupos de inmigrantes que aparecían en alguna trifulca tabernera, es decir, como insulto o de manera despectiva (Marín, 2001: 140). 
los estratos sociales migrantes más elevados, los cuales habrían abandonado progresivamente el barrio a partir de 1915 huyendo de la degradación que fue experimentando y de la llegada de otros grupos de migrantes (Olives, 1969). En los años 20, si no antes, la inmigración valenciana había traspasado los límites del centro de la ciudad y de los suburbios populares. Así, junto a la población aragonesa, era mayoría también en Trinitat Vella, un barrio al norte de la urbe, perteneciente al antiguo municipio de Sant Andreu del Palomar (Checa, 1999), una zona aún poco poblada en la que predominaba una zona de viñas y algunos masos.

Para el año 1930, los cabezas de familia inmigrantes valencianos presentaban una distribución en el espacio barcelonés "moderadamente nuclear" (Oyón et al., 2001: 70). Su presencia era muy destacada en algunas zonas de la ciudad -en el frente marítimo que va desde la Barceloneta al Poblenou, en el Poble-sec, en los barrios de Sants y Can Baró y en algunas áreas más dispersas- ${ }^{21}$ mientras que estaban ausentes en otras -el Eixample central y algunos suburbios del norte de la ciudad-. Con todo, la inmigración valenciana no llegaba a alcanzar unos índices de concentración tan elevados como la andaluza y la murciana, que se habían instalado en Barcelona con posterioridad. Además, aunque pertenecieran a la clase jornalera, el análisis de indicadores como el analfabetismo y la corresidencia no familiar situaba a la población valenciana en una posición socioeconómica más elevada (Oyón et al., 2001).

\section{Concentración y distribución de la inmigración valenciana en Barcelona}

Entre 1832, año en el que entró en funcionamiento la primera fábrica movida a vapor en Barcelona, y 1930, cuando se había consumado la revolución industrial en la ciudad, la capital catalana experimentó profundas transformaciones (Tatjer, 2006). En el ámbito territorial, pasó de ocupar $14 \mathrm{~km}^{2}$ a $70 \mathrm{kms}^{2}$ tras el proceso de anexión de los municipios colindantes llevado a cabo entre 1897 y 1921 (Masjuan, 2000). De esta manera, la ciudad extendió sus límites a los que -salvo ligeras modificaciones- conserva actualmente. ${ }^{22}$ Administrativamente, estaba dividida en 10 distritos, a su vez subdivididos en 131 barrios (Mapa 1).

${ }^{21}$ Además, gracias al trabajo de Oyón et al. (2001) conocemos no solo las principales áreas de origen, de asentamiento y ocupaciones de los migrantes valencianos en Barcelona, sino más características sociodemográficas como, por ejemplo, la distribución de los hogares valencianos, el tamaño medio de sus hogares (4,84 personas), el número de hijos medio de los cabezas de familia valencianos $(1,93)$ o la distribución de los cabezas de familia entre las diferentes clases sociales de 1930.

${ }^{22}$ Dichos límites son al norte el río Besos, al este el Mar Mediterráneo, al sur el río Llobregat y al oeste la sierra de Collserola. 


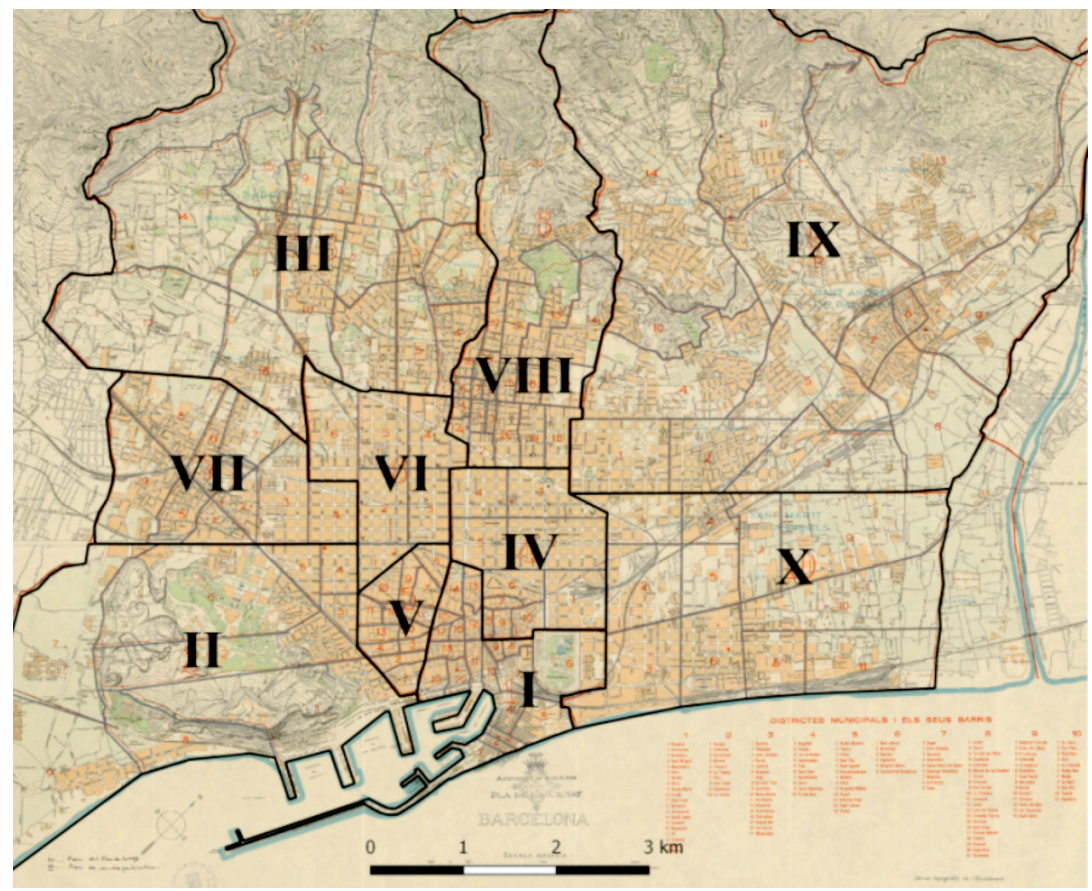

Mapa 1. Mapa de la ciudad de Barcelona en 1930, distritos (10) y barrios (131). Fuente: Elaboración propia a partir del mapa de Barcelona de 1930 proporcionado por el Servei Topogràfic de l'Ajuntament de Barcelona (autor: Seix Barral)

En el ámbito poblacional, de los 544 mil habitantes con los que contaba en 1900, en 1930 había traspasado la barrera del millón de habitantes, lo que suponía el crecimiento demográfico más espectacular de su historia en tan solo 30 años (Tatjer, 1995). ${ }^{23}$ Dicho crecimiento demográfico se produjo en parte por la incorporación de la población residente en los municipios agregados. Sin embargo, el gran factor del aumento poblacional de Barcelona en ese periodo fue la inmigración (García Castro, 1974, Cabré, 1991-1992, 1999; López-Gay, 2008). Como resultado, en 1930, el 56\% de la población barcelonesa había nacido fuera de la ciudad.

La inmigración peninsular no catalana, que constituía el 34\% del total, había sobrepasado ampliamente a la inmigración catalana (19\% entonces) desde

${ }^{23}$ Así, en 1930 se situaba como la decimotercera ciudad más poblada de Europa (Tatjer, 1995). A nivel estatal, Barcelona contaba con un censo de 1.009.755 personas, lo que la situaba por delante de Madrid, que en ese mismo momento contaba con 863.958 habitantes (Azagra et al., 2006). 
Tabla 1. Población barcelonesa según el distrito de residencia y su lugar de nacimiento, principales orígenes, 1930

\begin{tabular}{c|c|c|c|c|c|c|c|c}
\hline Distrito & $\begin{array}{c}\text { Barcelona } \\
\text { (capital) }\end{array}$ & $\begin{array}{c}\text { Resto de } \\
\text { Cataluña }\end{array}$ & $\begin{array}{c}\text { País } \\
\text { Valenciano }\end{array}$ & Aragón & Múrcia & Andalucía & Otros & Total casos \\
\hline I & $42 \%$ & $18 \%$ & $10 \%$ & $7 \%$ & $4 \%$ & $7 \%$ & $11 \%$ & 96.264 \\
\hline II & $42 \%$ & $18 \%$ & $11 \%$ & $7 \%$ & $6 \%$ & $5 \%$ & $12 \%$ & 91.838 \\
\hline III & $46 \%$ & $19 \%$ & $6 \%$ & $8 \%$ & $3 \%$ & $3 \%$ & $15 \%$ & 59.611 \\
\hline IV & $43 \%$ & $22 \%$ & $6 \%$ & $10 \%$ & $3 \%$ & $3 \%$ & $13 \%$ & 113.574 \\
\hline V & $41 \%$ & $18 \%$ & $10 \%$ & $9 \%$ & $7 \%$ & $4 \%$ & $12 \%$ & 107.889 \\
\hline VI & $40 \%$ & $23 \%$ & $6 \%$ & $9 \%$ & $2 \%$ & $3 \%$ & $16 \%$ & 94.611 \\
\hline VII & $43 \%$ & $18 \%$ & $12 \%$ & $7 \%$ & $6 \%$ & $4 \%$ & $9 \%$ & 115.809 \\
\hline VIII & $49 \%$ & $21 \%$ & $7 \%$ & $7 \%$ & $2 \%$ & $3 \%$ & $11 \%$ & 109.172 \\
\hline IX & $46 \%$ & $17 \%$ & $8 \%$ & $8 \%$ & $6 \%$ & $5 \%$ & $10 \%$ & 140.485 \\
\hline X & $44 \%$ & $19 \%$ & $12 \%$ & $8 \%$ & $5 \%$ & $4 \%$ & $9 \%$ & 80.502 \\
\hline Total casos & $44 \%$ & $19 \%$ & $9 \%$ & $8 \%$ & $4 \%$ & $4 \%$ & $12 \%$ & 1.009 .755 \\
\hline
\end{tabular}

Fuente: Elaboración propia a partir de la Gaseta Municipal de Barcelona, 6 de junio de 1932, n. $^{\circ} 22$

mediados del siglo XIX, cuando su presencia numérica era insignificante (López, 2004: 77). Además, en ningún distrito de la ciudad la inmigración no catalana constituía menos del 30\% de su población y llegaba a superar el $40 \%$ en los distritos I, II y V, que se corresponden con las áreas del casco histórico, Sant Antoni y Poble-sec.

La población valenciana constituía el grupo inmigratorio no catalán más numeroso en la ciudad de Barcelona. Con 88.298 personas, representaba el $8,74 \%$ del total de la población residente en el municipio, seguida por la población aragonesa con 81.368 personas, la murciana, con 45.047, y la andaluza, con 42.756 (Pujadas, 1982). A grandes rasgos, el cálculo del cociente de localización $(\mathrm{CL})^{24}$ muestra áreas de sobrerrepresentación coincidentes con las que hasta ahora se habían señalado como las de mayor representación de cabezas de familia valencianos (Oyón et al., 2001). De esta manera, se dibujan claramente tres zonas en las que la inmigración valenciana estaba sobrerrepresentada (Mapa 2). La primera, en el frente marítimo de la ciudad, de la

${ }^{24}$ EL CL es un indicador muy utilizado en la geografía o la economía que sirve para determinar el grado de concentración de un colectivo poblacional o una actividad económica en un área determinada en relación al conjunto. Para más información, véase Domingo y Pitarch (2015) o Brown y Chung (2006), por ejemplo. 


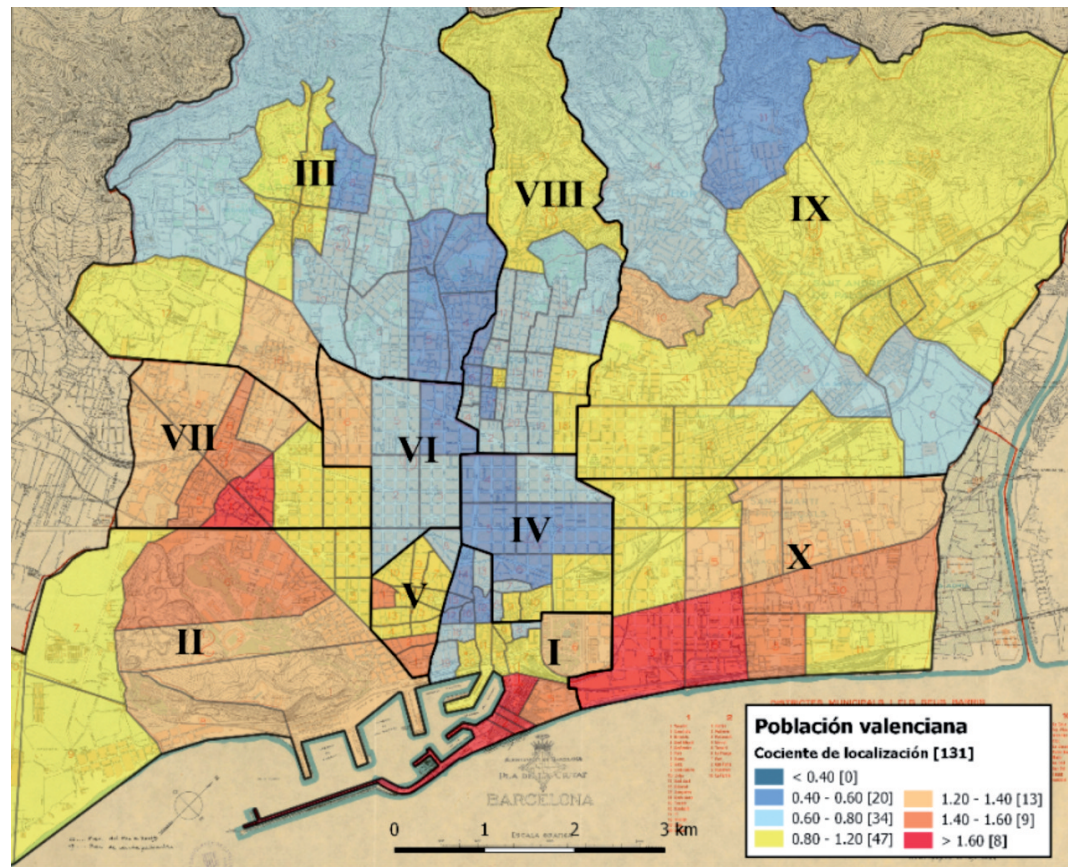

Mapa 2. Concentración (cociente de localización) de la inmigración valenciana por barrios de Barcelona, 1930.

Fuente: Elaboración propia a partir del mapa de Barcelona de 1930 proporcionado por el Servei Topogràfic de l'Ajuntament de Barcelona (autor: Seix Barral) y de la Gaseta Municipal de Barcelona, 6 de junio de 1932, n. ${ }^{\circ} 22$

Barceloneta, en el distrito I -donde se concentraban hasta 4.885 inmigrantes valencianos en poco más de $1 \mathrm{~km}^{2}-$ al Poblenou, en el distrito X. Esta zona se prolongaba hacia el interior de la ciudad en torno al Parc de la Ciutadella (barrio del Parc) y por algunos de los barrios interiores de Sant Martí más cercanos a Sant Adrià del Besós (La Llacuna, Malta, Can Pol y Taulat). La segunda se extendía desde los barrios de Sants, en el distrito VII -con Hostafrancs (entonces los barrios de Ángel y Creu Coberta) como área más destacada ${ }^{25}$ y atravesaba Poble-sec, en el distrito II, para expandirse hacia el interior del Raval, ocupando los barrios más cercanos al mar (Santa Mónica y Teatre) y, más al norte,

${ }^{25}$ En el actual barrio de Hostafrancs, en el distrito VII, encontramos dos de los seis barrios con los CL más altos de toda Barcelona: los antiguos Creu Coberta y Ángel, ambos con un CL del 1,9. 
el barrio de les Escoles Pies, todos en el distrito V. Y la tercera, aunque no con tanta intensidad, se situaba en Can Baró, una zona aislada en el distrito IX cuya urbanización se había iniciado en 1919.

Se corrobora, por tanto, que la inmigración valenciana se concentraba especialmente en barrios de marcado carácter obrero (Oyón et al., 2001: 70), la mayoría con núcleos de barracas y otros tipos de infravivienda dentro de sus fronteras, construidas en torno a las fábricas. Ahora bien, no puede decirse que su presencia se redujese a la Barcelona más obrera. Si abrimos el análisis a los números absolutos, se observa que no en todos los barrios donde la inmigración valenciana estaba infrarrepresentada estaba también ausente (Mapa 3). La inmigración valenciana era especialmente cuantiosa -más de 1.000 residentes- en diversas zonas relativamente bien delimitadas, situadas a ambos lados de un corredor central con menor presencia de valencianos, que, de mar a montaña, transcurría desde el Gòtic hasta los sectores colindantes con el Paseo de Gracia. Las zonas de mayor presencia se situaban en la parte meridional del Raval, toda la Esquerra de l'Eixample (Antiga y Nova), la Dreta de l'Eixample, Sagrada Familia, Guinardó, Camp de l'Arpa y, en menor medida, la Vila de Gràcia. Este último sector destacaba por concentrar talleres y fábricas textiles, pequeñas imprentas e industrias de calzado (Oliveras, 2013), oficio que contaba con una importante tradición en algunas comarcas valencianas, sobre todo alicantinas (Miranda, 1993).

Coincidentes con las áreas de sobrerrepresentación observadas a través del CL, encontramos dos zonas de marcado carácter obrero: la zona de Sants y Hostafrancs ${ }^{26}$ que se extiende, en dirección sureste, a los barrios de La França y Pedreres en Montjuic, y la segunda, que transcurre por el frente costero desde la Barceloneta hasta prácticamente la frontera con Sant Adrià del Besòs, pasando por el Gasómetro, el antiguo municipio de Sant Martí de Provençals y los barrios de Poblenou y Taulat. En la primera de estas áreas, además de poblados de barracas, como se ha señalado, se ubicaban gran cantidad de fábricas, sobre todo de cerámica en el entorno de Hostafrancs. Y es que en este barrio se reunía hasta el 50\% de los trabajadores de Barcelona que trabajaban en las empresas de cerámica (Tatjer, 1995). Muchos de ellos procedían de la provincia de Castellón y habrían llegado al barrio a partir de los años 60 del siglo XIX con la instalación de las primeras azulejeras y fábricas de ladrillos (Fabre

\footnotetext{
${ }^{26}$ Formada por los Barrios de Tena, Coll-Blanc, Espanya Industrial, Creu Coberta, Àngel, Rocafort y Santa María de Sants, todos ellos con más de 1.000 valencianos registrados en cada uno. Dicha área también es citada por Oyón et al. (2001) por destacar como una importante zona de concentración valenciana, más concretamente de gente del interior de Castellón.
} 


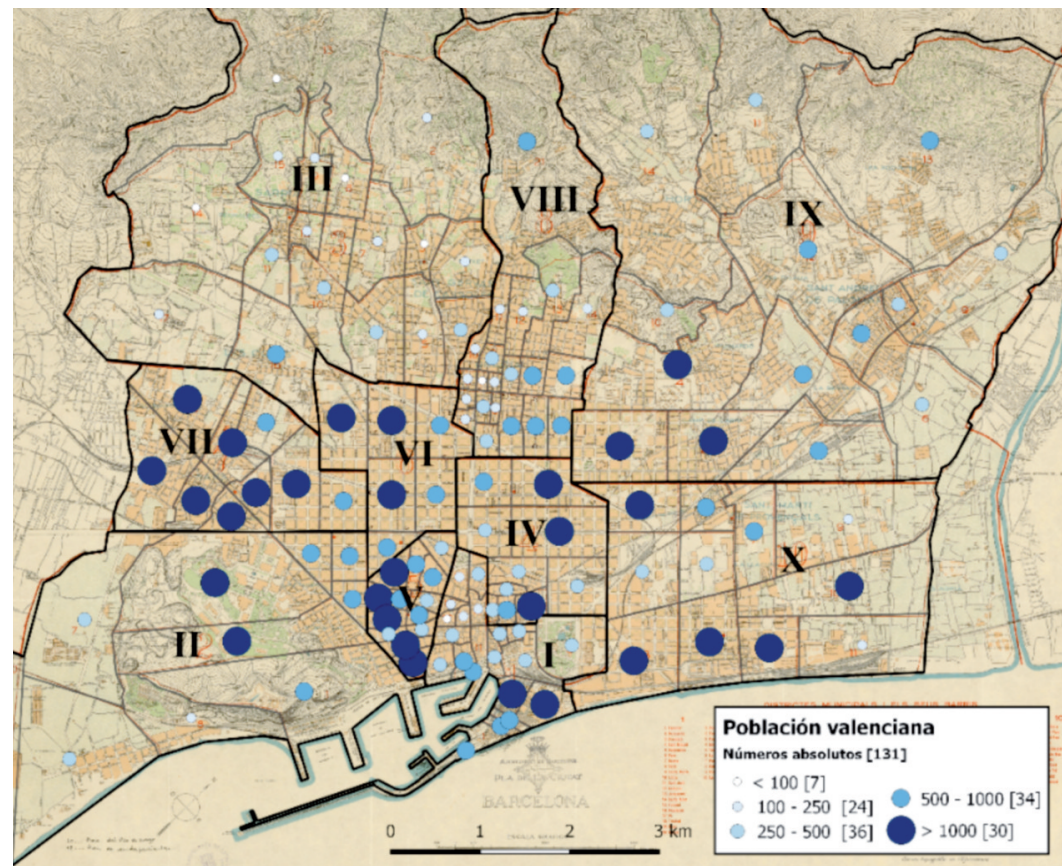

Mapa 3. Distribución de la inmigración valenciana por barrios de Barcelona, 1930. Fuente: Elaboración propia a partir del mapa de Barcelona de 1930 proporcionado por el Servei Topogràfic de l'Ajuntament de Barcelona (autor: Seix Barral) y de la Gaseta Municipal de Barcelona, 6 de junio de 1932, n. ${ }^{\circ} 22$

i Huertas, 1976; Ortells, 2005). ${ }^{27}$ De hecho, solo en el distrito VII se agrupaba una cuarta parte de los inmigrantes de la provincia de Castellón que vivían en toda la ciudad en 1930. En la segunda área, la más cercana al mar, además de ubicarse algunas industrias vinculadas a la reparación naval, otras pioneras en la construcción de maquinaria de vapor, la primera empresa de producción de gas (Tatjer, 2006) o el complejo textil de Can Ricart, también se concentraban los poblados barraquísticos del Somorrostro, del cementerio de Poblenou y de la Mar Bella, en los cuales está documentada la presencia valenciana. ${ }^{28}$

${ }^{27}$ Entre ellos el famoso doctor Corachán, una de las figuras clave de la medicina catalana que emigró a casa de unos tíos valencianos que tenía en el barrio en 1893.

${ }^{28}$ Así lo atestigua, por ejemplo, el escritor Julià Guillamon sobre su padre, nieto de castellonenses emigrados a Barcelona en los años 20 desde Toga (Castellón): "mi padre explicaba siempre que había nacido en las barracas de detrás del Cementerio del Este. Cuando yo era pequeño todavía vivían unos medio familiares. Recuerdo haber estado en la casa, que no tenía nada de barraca: era una casa sencilla con paredes emblanquinadas". (Guillamon, 2018: 34). 
Sin embargo, como apuntábamos, la presencia de la inmigración valenciana era también muy destacada en otras zonas que no muestran un elevado índice de concentración y que se corresponden, algunas, con una inmigración fundamentalmente femenina (Mapa 4). La primera área se corresponde con una Barcelona apenas obrera, todo lo contrario, se trata de un área que destaca por la concentración de clases bienestantes (Oyón et al., 2001) y que empieza en la parte más alta de la ciudad, Sarrià y Sant Gervasi, para atravesar la Esquerra de l'Eixample -especialmente la zona en torno al Hospital Clínic y la Escola Industrial- ${ }^{29}$ y descender hacia los barrios del Raval fronterizos con el Poble-sec y delimitados por la avenida del Paral-lel, les Rondes de Sant Pau i Sant Antoni (Marqués del Duero en 1930). ${ }^{30}$ La elevada tasa de feminización de la inmigración valenciana en algunos de estos barrios, como los del Eixample, tanto la Esquerra (Hospital Clínic) como la Dreta (Saleses) (Mapa 4), nos remiten a una inmigración ligada a un mercado de trabajo específicamente femenino. Por un lado, al trabajo que generaban las órdenes religiosas (el caso del convento femenino de Las Arrepentidas en el barrio del mismo nombre en el distrito VII) y los hospitales (como el barrio del Hospital Clínic en el distrito VI), en los que las monjas se ocupaban de las tareas de enfermería. Por otro lado, al servicio doméstico, actividad que se concentraba en esa zona central (Oyón et al., 2001: 24), zona que presentaba una tasa de feminización altísima, muy por encima de la tasa de feminización de la ciudad, situada en torno al 111\% (Villar, 2018). Las inmigrantes valencianas, con el 12\% del total de las sirvientas de la ciudad, constituían el segundo grupo migratorio más numeroso en esta ocupación, solo por detrás de las aragonesas, que representaban el 24\% (Borrell, 2015: 49, 74). El servicio doméstico constituía, por detrás de la industria textil, el segundo nicho laboral femenino más importante de la ciudad y había aumentado sus efectivos considerablemente desde, al menos, el último cuarto del siglo XIX. Así, el número de mujeres ocupadas como sirvientas en Barcelona había pasado entre 1860 y 1930 de algo más de 12.000 a casi 30.000. También las órdenes religiosas habían aumentado sus efectivos femeninos considerablemente en ese periodo: de apenas 800 monjas en 1860, la ciudad contaba con casi 3.600 en 1930 (Borrell, 2015: 49 y 74).

La segunda área, que discurría en paralelo a la primera, dibuja una línea casi recta que se inicia en la parte más alta del actual barrio de Sant Pere y atraviesa toda la Dreta de l'Eixample, para alargarse por, prácticamente, todos los barrios de Gràcia y Vallcarca, del distrito IV al distrito VIII. Se trata de una

\footnotetext{
${ }^{29}$ En concreto los barrios 2, 5 y 6 del distrito II.

${ }^{30}$ Santa Mònica, Teatre, Sant Pau, Presó, Les Escoles Pies y Padró.
} 


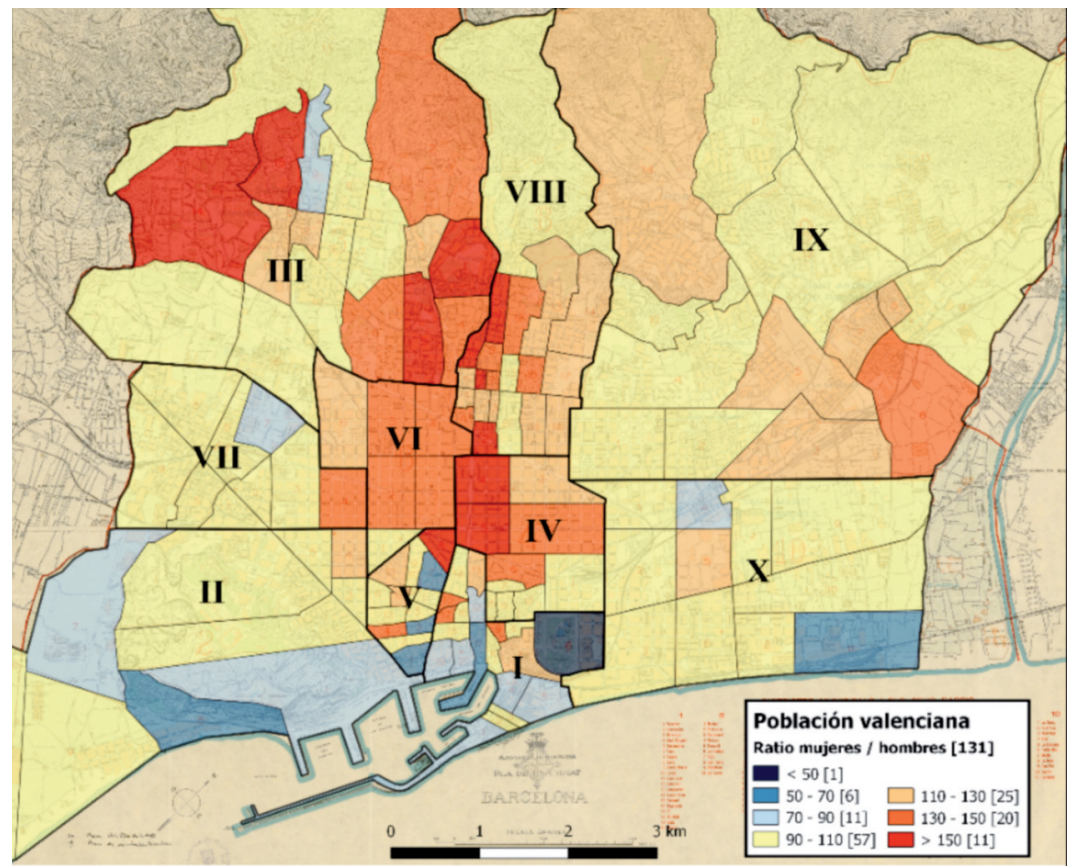

Mapa 4. Tasa de feminización por barrios de Barcelona, migración valenciana, 1930. Fuente: Elaboración propia a partir del mapa de la Barcelona de 1930 proporcionado por el Servei Topogràfic de l'Ajuntament de Barcelona (autor: Seix Barral) y de la Gaseta Municipal de Barcelona, 6 de junio de 1932, n. ${ }^{\circ} 22$.

zona mixta, donde vivían sectores de las clases más altas y medias, sobre todo en la Dreta de l'Eixample, y las clases más populares y obreras, si nos referimos al barrio de Gràcia. En estas últimas zonas destacaban fábricas textiles de tamaño medio y grande, como Can Ramis y la de Pelegrí Vilaregut (Oliveras, 2013).

Por último, cabe decir que, aunque no es una área que destaque por una elevada presencia de inmigración valenciana, existe una tercera zona aislada del resto y situada en torno al antiguo núcleo de la Sagrera ${ }^{31}$ que sí sobresale por la elevada tasa de feminización de dicha inmigración, lo que podría estar relacionado con la presencia de la fábrica textil Fabra y Coats, que llegó a emplear a unas 3.000 personas (Oliveras, 2013). Era, además, una zona que

${ }^{31}$ Hasta finales del siglo XIX esta zona estaba escasamente poblada, pero a partir de 1878 experimentó un destacado crecimiento urbano -después de que se anunciase la construcción de una línea de tranvía (Pallares, 2014)-, que se consolidó en las primeras décadas del XX, con la creación de la fábrica Hispano Suiza y el inicio de las obras para la construcción de la estación de mercancías (Checa, 1997). 
registraba una de las mayores intensidades de infravivienda de toda la ciudad en 1930 (Oyón et al., 2001), lo que indicaría que estamos delante de una zona con predominio de proletariado femenino inmigrante.

En definitiva, podemos concluir que la inmigración valenciana mostraba en la Barcelona de 1930 una concentración moderadamente nuclear en determinadas zonas de marcado carácter obrero. Sin embargo, se ha observado también una presencia numérica muy importante en zonas con mayor diversidad social, como el Eixample o el Raval. Y, lo que es más relevante, que en estas zonas existía una presencia extraordinaria de la inmigración femenina valenciana desconocida hasta ahora.

\section{La inmigración valenciana en la Barceloneta}

La Barceloneta, barrio marítimo de Barcelona fundado a mediados del siglo XVIII, ejemplifica a la perfección las transformaciones que sufrió Barcelona en su morfología urbana. Situada en un pequeño apéndice triangular al sureste de la ciudad, la Barceloneta (Mapas 5 y 6) se construyó como arrabal marítimo sobre núcleos de barracas de gente de mar (pescadores, calafates y matriculados). Desde mediados del siglo XIX experimentó una profunda conversión en un área industrial (especialmente relevante era la presencia de grandes talleres metalúrgicos), portuaria, obrera e incluso de esparcimiento -con la creación de instalaciones recreativas como baños de mar o la plaza de toros- y perdió paulatinamente su función marítima (Tatjer, 1973). Dicho cambió se acentuó a lo largo del primer tercio del siglo XX, cuando experimentó un pro-
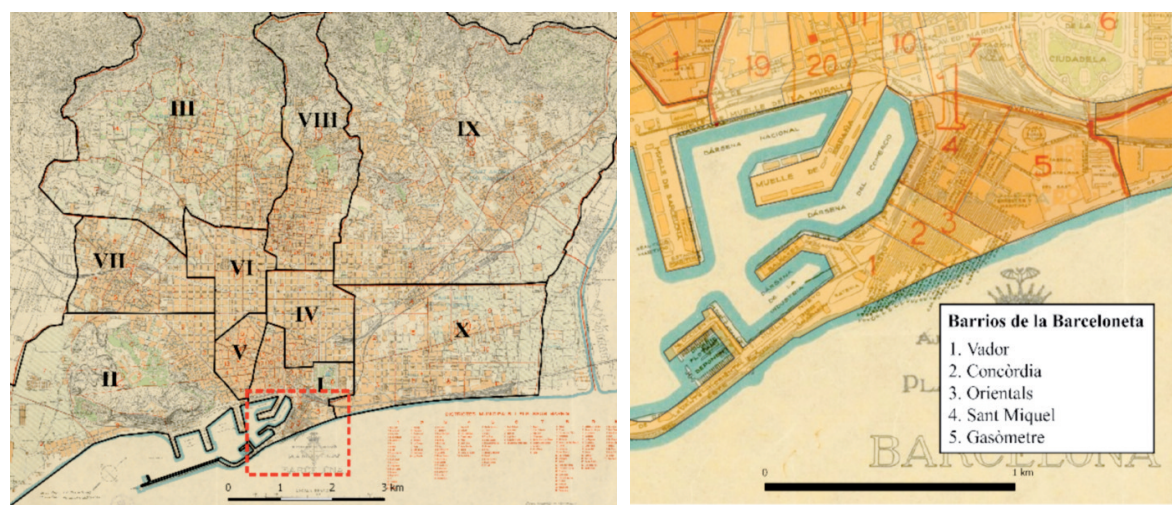

Mapas 5 y 6. Mapas de Barcelona con la localización del barrio de la Barceloneta, 1930. Fuente: Elaboración propia a partir del mapa de Barcelona de 1930 proporcionado por el Servei Topogràfic de l'Ajuntament de Barcelona (autor: Seix Barral) 
ceso de proletarización y de empeoramiento de las condiciones de vivienda. Perdió variedad social y se empobreció, lo que la convirtió en un gueto proletario con cotas muy altas de inmigración no catalana y de analfabetismo (Tatjer 1973: 73-74; Oyón, 2008). A consecuencia de ese triple proceso -inmigración, densificación, empobrecimiento-, en 1930 se había transformado en un barrio de inmigración obrera densificado, una de las áreas más proletarias de la ciudad, terriblemente hacinada y con fuerte incidencia del realquiler (Oyón, 2008: 120-125).

En este contexto, como habíamos avanzado, la Barceloneta constituía en 1930 una de las zonas de la ciudad con mayor presencia de la inmigración valenciana. De hecho, este colectivo representaba el $18 \%$ de la población total en Concòrdia y el $17 \%$ en Orientals, sus barrios centrales, un porcentaje superado únicamente por los nacidos en la ciudad con un 46\% y $47 \%$ respectivamente (Tabla 2). Además, los migrantes valencianos estaban sobrerrepresentados en cuatro de los cinco barrios que componían la Barceloneta. De hecho, en los dos barrios centrales, el cálculo del CL arrojaba, con un 2, los mayores valores de toda la ciudad. Es decir, la concentración de valencianos en estas dos áreas era el doble de lo que tendría que ser si los valencianos se repartiesen de una manera uniforme por la ciudad. El análisis que llevamos a cabo, centrado en estas dos áreas contiguas (Mapa 6), deviene de especial interés para saber cómo se organizaba la vida de este grupo de población inmigrante en la parte más residencial de la Barceloneta, un sector destinado intensivamente a viviendas con comercio en los bajos y algunos edificios públicos (Tatjer, 1972).

Tabla 2. Composición por origen de la población de la Barceloneta según el barrio, principales orígenes, 1930

\begin{tabular}{c|c|c|c|c|c|c|c|c}
\hline Barrios & $\begin{array}{c}\text { Barcelona } \\
\text { (capital) }\end{array}$ & $\begin{array}{c}\text { Resto de } \\
\text { Cataluña }\end{array}$ & $\begin{array}{c}\text { País } \\
\text { Valenciano }\end{array}$ & Aragón & Múrcia & Andalucía & Otros & Total casos \\
\hline Sant Miquel & $46,0 \%$ & $12,4 \%$ & $15,6 \%$ & $5,4 \%$ & $4,1 \%$ & $8,3 \%$ & $8,2 \%$ & 8.406 \\
\hline Gasòmetre & $40,0 \%$ & $9,1 \%$ & $12,4 \%$ & $5,5 \%$ & $7,1 \%$ & $16,3 \%$ & $9,6 \%$ & 8.327 \\
\hline Concòrdia & $45,5 \%$ & $8,3 \%$ & $17,9 \%$ & $2,2 \%$ & $5,5 \%$ & $13,4 \%$ & $7,2 \%$ & 5.367 \\
\hline Orientals & $47,0 \%$ & $8,6 \%$ & $17,4 \%$ & $3,3 \%$ & $6,5 \%$ & $9,8 \%$ & $7,3 \%$ & 5.162 \\
\hline Escar & $48,9 \%$ & $10,1 \%$ & $15,8 \%$ & $1,6 \%$ & $3,5 \%$ & $13,9 \%$ & $6,1 \%$ & 4.328 \\
\hline Total Barceloneta & $44,9 \%$ & $9,9 \%$ & $15,5 \%$ & $4,0 \%$ & $5,5 \%$ & $12,3 \%$ & $8,0 \%$ & $100 \%$ \\
\hline Total casos & $\mathbf{1 4 . 1 8 4}$ & $\mathbf{3 . 1 3 0}$ & $\mathbf{4 . 8 8 5}$ & $\mathbf{1 . 2 6 8}$ & $\mathbf{1 . 7 2 2}$ & $\mathbf{3 . 8 8 8}$ & $\mathbf{2 . 5 1 3}$ & $\mathbf{3 1 . 5 9 0}$ \\
\hline
\end{tabular}

Fuente: Elaboración propia a partir de la Gaseta Municipal de Barcelona, 6 de junio de $1932, n^{\circ} 22$ 
La estructura demográfica, los orígenes geográficos y la llegada a Barcelona

Nuestro análisis se centra en una muestra de 254 hogares en los que residía, al menos, una persona valenciana y en los cuales se empadronaron en 1930 1.121 personas, de las cuales 552 (267 hombres y 285 mujeres) habían nacido en el País Valenciano (Figura 1). Estos valencianos y valencianas constituían un colectivo joven, especialmente los hombres, y la mayoría -en torno al 80\% tanto en hombres como mujeres- estaba en edad de trabajar. ${ }^{32}$ Los hombres, con una edad media de 35,6, años predominaban en prácticamente todas las franjas de edad hasta los 44 años y estaban casados, en su mayoría, a partir de los 30 años (entre los 20 y los 29 solo un 36,5\% lo estaba). Las mujeres, en cambio, con una edad media de 39 años, eran mayoría en las franjas de edad a partir de los 40 años, una estructura que refleja la mayor esperanza de vida femenina, lo que se corresponde también con una mayor presencia de viudas a partir de los 44 años. Además, las casadas, mayoría en la franja de los 2029 años, eran más jóvenes que los hombres, lo que se corresponde con la tendencia general del acceso al matrimonio de los hombres a edades más tardías que en el caso de las mujeres (Cabré, 1999).

Estamos, por tanto, ante un colectivo de adultos jóvenes, la mayor parte de los cuales, un $62 \%$, procedía de la provincia de Alicante, mientras que un $29 \%$ procedía de la provincia de Castellón y solo un 9\% de la provincia de Valencia. Esta distribución está en total consonancia con la composición general de la inmigración valenciana en la Barceloneta, donde predominaba la población procedente de la costa de Alicante y de algún puerto costero castellonense como Vinaròs, mientras que en el conjunto de la ciudad era mayoría la población procedente de la provincia de Valencia y de Castellón (Tatjer, 1973; Oyón et al., 2001).

Respecto al momento de llegada a la ciudad, y sin que se aprecien, en general, diferencias entre hombres y mujeres, ésta se produjo en aumento progresivo desde finales del siglo XIX. Alrededor de un 17\% de estos inmigrantes llegaron a la ciudad antes de 1900, un 21\% en la primera década del siglo XX, casi un 28\% lo hizo en la segunda década y algo más del 32\% en los años 20 (Tabla 3). Por su parte, alicantinos y castellonenses, especialmente estos últimos, habían seguido esa pauta de llegada en aumento progresivo, y llegaron

\footnotetext{
32 Consideramos edad de trabajar entre los 14 y los 64 años. Los 14 constituía en esa fecha la edad legal para trabajar y al cumplir los 65 años se quedaba excluido de la cotización al Retiro Obrero. Artículo 9. ${ }^{\circ}$ del Reglamento General para el Régimen Obligatorio del Retiro Obrero de 21 de enero de 1921 (Gaceta de Madrid del 23 de enero de 1921), disponible en http://fama2.us.es/fde/ocr/2007/reglamentoGeneralParaElRegimenObligatorio.pdf (consultado el 11/12/2017).
} 
Figura 1. Estructura por edades de la población en hogares valencianos en la Barceloneta, 1930

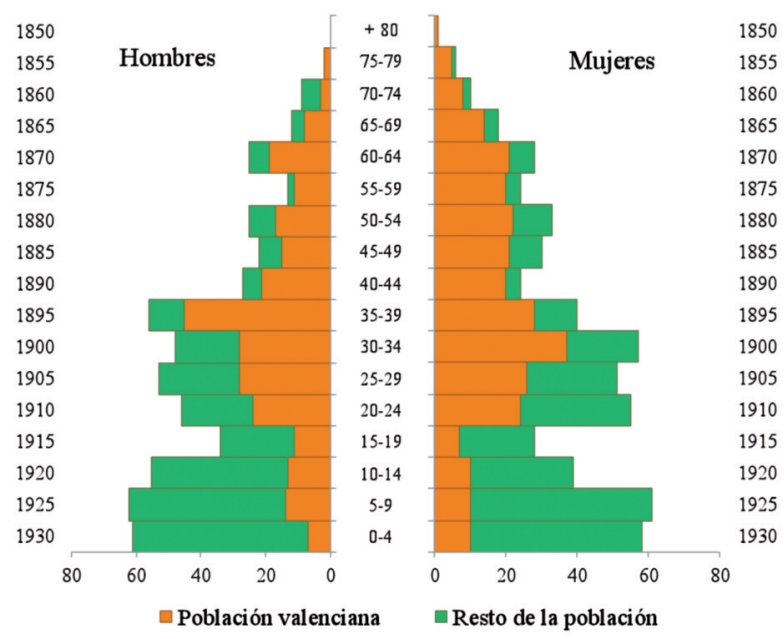

Fuente: Elaboración propia a partir de la muestra del Padrón Municipal de Habitantes de Barcelona, 1930

a la ciudad sobre todo a partir de 1911 (un 64\% desde Alicante y un 53\% desde Castellón). Sin embargo, quienes procedían de la provincia de Valencia llegaron, en su mayoría, antes de 1920, especialmente antes de 1900 (33\%) y después de 1911 (29\%). Y es que el flujo migratorio desde la provincia de Valencia a la ciudad de Barcelona experimentó numerosos altibajos a lo largo de todo el periodo, oscilaciones relacionadas con el crecimiento económico y demográfico de la capital valenciana a principios del siglo XX (Baila, 1994). Dicho crecimiento la convirtió en un centro receptor de mano de obra inmigrante al tiempo que mitigó las salidas hacia el exterior, fenómeno que, sin embargo, no se extendió al conjunto del País Valenciano, cuyo saldo migratorio se mantuvo notablemente negativo durante estos años. ${ }^{33}$

La mayoría de estos inmigrantes llegó a la ciudad a una edad muy temprana. Un 34\% lo hizo antes de cumplir los 14 años o siendo mayor de 25 años (28\%) (Tabla 4), edad a partir de la cual, como hemos visto, tanto hombres como mujeres, aunque sobre todo éstas, estaban casadas. Se trata, por tanto, de un

33 Solo entre 1900 y 1930 Valencia capital tuvo un saldo migratorio positivo de más de 81 mil personas, mientras que en el resto del País Valenciano el saldo fue negativo y de unas 144 mil personas (Baila, 1994). 
Tabla 3. Inmigración valenciana en la Barceloneta según su origen provincial y sexo, momento de llegada a Barcelona, 1930

\begin{tabular}{c|c|c|c|c|c|c|c}
\hline Llegada & Hombres & Mujeres & Total & Alicante & Castelló & València & Total casos \\
\hline s. XIX & $18 \%$ & $16 \%$ & $17 \%$ & $13 \%$ & $22 \%$ & $33 \%$ & 95 \\
\hline $1901-1910$ & $20 \%$ & $23 \%$ & $21 \%$ & $20 \%$ & $26 \%$ & $16 \%$ & 118 \\
\hline $1911-1920$ & $27 \%$ & $29 \%$ & $28 \%$ & $30 \%$ & $23 \%$ & $29 \%$ & 153 \\
\hline $1921-1930$ & $33 \%$ & $31 \%$ & $32 \%$ & $34 \%$ & $30 \%$ & $22 \%$ & 176 \\
\hline Sin datos & $2 \%$ & $1 \%$ & $1 \%$ & $3 \%$ & $0 \%$ & $0 \%$ & 10 \\
\hline Total casos & $\mathbf{2 6 7}$ & $\mathbf{2 8 5}$ & $\mathbf{5 5 2}$ & $\mathbf{3 4 1}$ & $\mathbf{1 6 0}$ & $\mathbf{5 1}$ & $\mathbf{5 5 2}$ \\
\hline
\end{tabular}

Fuente: Elaboración propia a partir de la muestra del Padrón Municipal de Habitantes de Barcelona, 1930

colectivo que emigró mayoritariamente en familia, concretamente en los primeros estadios del ciclo familiar. La llegada en familia se ha observado también en el caso de la inmigración andaluza residente en la Barceloneta en esta misma fecha (Tatjer, 1980; Villar, 2013) y constituye un rasgo característico de las corrientes migratorias hacia los núcleos en proceso de industrialización en toda Europa (González y García, 2006). ${ }^{34}$ Además, el aumento del porcentaje de la llegada de los jóvenes de mayor edad (entre 14 y 16 años) en la década de 1910 -coincidiendo con el momento de máximo aumento de la inmigración valenciana en Cataluña (Oyón et al., 2001) - y el sostenimiento de unas llegadas protagonizadas por adultos entre los 35 y 44 años durante todo el periodo nos indican el continuo flujo de familias que habrían traspasado ya los primeros estadios de su formación y que habrían emigrado con la perspectiva de integrar, si no a todos, sí a la mayor parte de sus miembros en el mercado laboral barcelonés.

\footnotetext{
${ }^{34}$ En el caso del área metropolitana de la Ría de Bilbao, estos autores cuantifican la inmigración correspondiente al núcleo familiar alrededor del $70 \%$ del total de inmigrantes, tanto durante la primera fase de la industrialización (1884-1900) como a mediados de la segunda, en los años 70 del siglo XX. Algunas investigaciones que han puesto de manifiesto la relevancia del modelo migratorio familiar citadas por estos autores son Doherty (1985), Hareven (1993), Arbaiza (1998), González (2001) y García (2005). En el caso de Cataluña, el estudio de Camps (1995: 98-111) sobre Sabadell muestra que la inmigración estaba compuesta, sobre todo, de familias que decidían moverse en las primeras fases de su ciclo de formación con varios hijos menores de 14 años y con una media de 4-5 personas. Este tipo de emigración parece también haber sido característica en el caso de los jornaleros inmigrantes en el Madrid de finales del siglo XIX (Pallol, 2004).
} 
Tabla 4. Inmigración valenciana en la Barceloneta según el momento y la edad de llegada. Barcelona, 1930

\begin{tabular}{|c|c|c|c|c|c|}
\hline \multirow{2}{*}{ Edad } & \multicolumn{5}{|c|}{ Hombres } \\
\hline & S. XIX & 1901-1910 & 1911-1920 & $1921-1930$ & Total casos \\
\hline $00-13$ & $51 \%$ & $46 \%$ & $31 \%$ & $31 \%$ & $37 \%$ \\
\hline $14-24$ & $14 \%$ & $17 \%$ & $32 \%$ & $20 \%$ & $21 \%$ \\
\hline $25-44$ & $31 \%$ & $30 \%$ & $26 \%$ & $28 \%$ & $28 \%$ \\
\hline$>44$ & $0 \%$ & $4 \%$ & $4 \%$ & $3 \%$ & $3 \%$ \\
\hline Total casos & 49 & 54 & 72 & 87 & 262 \\
\hline \multirow{2}{*}{ Edad } & \multicolumn{5}{|c|}{ Mujeres } \\
\hline & S. XIX & 1901-1910 & 1911-1920 & 1921-1930 & Total casos \\
\hline $00-13$ & $41 \%$ & $31 \%$ & $28 \%$ & $30 \%$ & $31 \%$ \\
\hline $14-24$ & $26 \%$ & $22 \%$ & $32 \%$ & $20 \%$ & $25 \%$ \\
\hline $25-44$ & $28 \%$ & $23 \%$ & $19 \%$ & $24 \%$ & $23 \%$ \\
\hline$>44$ & $0 \%$ & $8 \%$ & $4 \%$ & $2 \%$ & $4 \%$ \\
\hline Total casos & 46 & 64 & 81 & 89 & 284 \\
\hline \multirow{2}{*}{ Edad } & \multicolumn{5}{|c|}{ Total casos } \\
\hline & S. XIX & $1901-1910$ & $1911-1920$ & $1921-1930$ & Total casos \\
\hline $00-13$ & $46 \%$ & $38 \%$ & $29 \%$ & $31 \%$ & $34 \%$ \\
\hline $14-24$ & $20 \%$ & $19 \%$ & $32 \%$ & $20 \%$ & $23 \%$ \\
\hline $25-44$ & $29 \%$ & $26 \%$ & $22 \%$ & $25 \%$ & $25 \%$ \\
\hline$>44$ & $0 \%$ & $6 \%$ & $4 \%$ & $3 \%$ & $3 \%$ \\
\hline Total casos & 95 & 118 & 153 & 178 & 552 \\
\hline Edad & S. XIX & $1901-1910$ & $1911-1920$ & $1921-1930$ & Total casos \\
\hline $14-16$ & $6 \%$ & $4 \%$ & $10 \%$ & $3 \%$ & $6 \%$ \\
\hline $35-44$ & $4 \%$ & $7 \%$ & $6 \%$ & $6 \%$ & $6 \%$ \\
\hline
\end{tabular}

Fuente: Elaboración propia a partir de la muestra del Padrón Municipal de Habitantes de Barcelona, 1930

Estos resultados, por tanto, nos remiten a una gran importancia de la inmigración familiar en el flujo migratorio a la ciudad condal desde el País Valenciano, sin olvidar, sin embargo, que hay numerosas pistas que apuntan a la importancia de una corriente inmigratoria de mujeres valencianas en solitario. Dicho flujo estaría relacionado con la gran demanda de mano de obra femenina -especialmente joven adulta- que generaba el mercado de trabajo barcelonés, espe- 
cialmente en torno al servicio doméstico, en el que, como hemos apuntado, las valencianas tenían una presencia destacada en 1930. Muchas de estas valencianas, que en 1930 estaban casadas y con hijos, ni compartían procedencia con sus maridos ni habían llegado en la misma fecha que ellos, lo que apunta, junto a la elevada edad en la que se instalaron en la ciudad, a una más que probable llegada en solitario..$^{35}$ No es extraño, puesto que, ya desde finales del siglo XIX la mayor parte de la inmigración que llegaba a Barcelona era joven y soltera (Mora, 2010: 99; López-Gay, 2014) y, especialmente, femenina, como se aseguraba desde la propia Oficina Estadística Municipal. ${ }^{36}$ Por ese motivo, la tasa de feminidad de la ciudad, baja a mediados del siglo XIX, en 1900 se había situado en 109,25, para subir, en 1930, hasta el 111,84. ${ }^{37}$

\section{Estatus sociolaboral: cualificación e instrucción}

Si nos atenemos a los datos laborales masculinos, la inmigración valenciana de la Barceloneta formaba parte de la clase obrera ocupada en posiciones laborales que, de acuerdo con el esquema HISCLASS, se sitúan en la parte baja de la escala socioeconómica. ${ }^{38}$ Poco podemos decir de las actividades que desarrollaban las mujeres valencianas de la Barceloneta: en un abrumador $80 \%$, quedaron registradas en el padrón con la ocupación "sus labores". Y, aunque hemos podido comprobar en algunos casos que esto no era así, ${ }^{39}$ carecemos de datos que nos permitan cuantificar el subregistro de la actividad remunerada entre estas mujeres, un fenómeno que es habitual en los padrones municipales

${ }^{35}$ Es el caso, por ejemplo, de R.G.D. Nacida en Benidorm, se instaló en Barcelona en 1907, con 26 años. En 1930, residía con su marido, que había llegado a Barcelona un año antes, en 1906, a los 31 años, procedente de Alicante y sus tres hijos de 14, 12 y 10 años, los tres nacidos en la ciudad. Convivía con ellos la hermana soltera de R.G.D., que también había nacido en Benidorm y que había llegado a Barcelona con 38 años, en 1914.

${ }^{36}$ Así, en 1934, en la estadística resumen elaborada a partir de los datos del Padrón Municipal de habitantes de 1930, se aseguraba que en Barcelona "les dones arriben en la mateixa o major proporció que els homes" (Anexo a la Gaseta Municipal de Barcelona. Resums demogràfics de l'any 1934, Impremta de la Casa de la Caritat, 1934: 25).

${ }^{37}$ Según datos del Censo Nacional de Población.

${ }^{38}$ Para la clasificación de las ocupaciones con códigos HISCO se han aplicado los criterios establecidos para el contexto catalán en Van Leeuewn y Maas (2011) y Pujadas et al. (2014).

${ }^{39}$ Así, por ejemplo, A.D.L. (Grao de Gandia-València), soltera de 30 años, A.G.D. (Orihuela, Alicante), casada de 21 años, y S.C.B. (Vinaròs, Castellón) casada de 29 años, fueron registradas con ocupación "sus labores" a pesar de que las tres trabajaban, en el momento de la elaboración del padrón, en la empresa Hijos de Gerardo Bertrán, una empresa metalúrgica dedicada a la elaboración de envases litografiados, situada en el margen de la Barceloneta y el Poblenou (según datos de sus "vidas laborales" reconstruidas a partir de los registros de cotización a los seguros sociales. Para más información sobre dicha reconstrucción, véase Villar, 2013). 
de habitantes. ${ }^{40}$ Cabe destacar, sin embargo, que en los casos en los que se declaró una ocupación remunerada, éstas coinciden con ocupaciones situadas en los grupos de media-baja cualificación en los que se ocupaban los hombres. Así, quienes declararon ejercer una ocupación remunerada, ésta estaba vinculada mayoritariamente al peonaje en la industria (jornalera, obrera), a la industria textil, a la confección y a los servicios personales. Estos oficios, aunque muchos de ellos podían desempeñarse en fábricas, eran también habitualmente desarrollados en los propios domicilios particulares, en instituciones públicas (como el planchado en hospitales) o incluso en el espacio urbano público (las lavanderas).

Entrando ya a analizar las profesiones masculinas, como avanzábamos, la mayoría se sitúa en los grupos de media-baja cualificación. Solo un 7,7\% ejercía profesiones vinculadas a la administración y el comercio y otro 7,3\% ejercía profesiones industriales que requerían un cierto grado de cualificación -mecánicos, zapateros, carpinteros, etcétera-. El resto, un 34\%, se dedicaba a las "nobles y azarosas ocupaciones de mar", ${ }^{41}$ eran los pescadores (21\%) y marineros (21\%), mientras que la mayor parte, un $44 \%$, se declaraba como jornalero o similar -trabajador, obrero, mozo (Tabla 5)-. Entre estos últimos, buena parte debía ocuparse en tareas portuarias, ya que en la Barcelona de 1930 los jornaleros eran una de las tres principales categorías de este sector -junto con los capataces y controladores-, encargados de labores como la carga y descarga (Ibarz, 2003). Además, por un lado, la mayoría de los trabajadores portuarios en los años 30 residía en el entorno del puerto (Suarez e Ibarz, 1998; Ibarz, 2008), mientras que, por el otro, el País Valenciano, especialmente la provincia de Castellón y las zonas costeras de Alicante, proporcionó un importantísimo contingente de mano de obra dedicada a esta actividad a lo largo de la primera mitad del siglo XX. De hecho, a principios de 1940, una cuarta parte de la fuerza laboral portuaria de Barcelona provenía de este territorio (Ibarz, 2010).

${ }^{40}$ En el caso del padrón de 1930, en Barcelona se ha constatado que tanto entre las mujeres inmigrantes de la clase obrera jornalera más desfavorecida residentes en la Barceloneta y el Poblenou como entre las trabajadoras textiles de una de las más importantes empresas textiles, La España Industrial, en Sants, el subregistro de la actividad femenina alcanzaba, como mínimo, el 60\% (Borderías et al., 2011: 72; Villar, 2016: 7). Sobre las causas del subregistro del trabajo femenino en las fuentes estadísticas oficiales, véase Humphries y Sarasúa (2012).

${ }^{41}$ En palabras de Guitert de Cubas, que hablaba de una migración valenciana dedicada básicamente a tareas marítimas y que habría empezado a llegar a principios del siglo XIX del antiguo Reino de Valencia a la Barceloneta (Tatjer, 1973: 105). 
Tabla 5. Ocupación de los valencianos (mayores de 14 años) residentes en la Barceloneta según el momento de llegada a la ciudad, Barcelona, 1930

\begin{tabular}{|c|c|c|c|c|c|}
\hline \multicolumn{3}{|c|}{ Grupo Hisclass } & Hasta 1914 & $1915-1930$ & Total casos \\
\hline 4 & \multicolumn{2}{|c|}{$\begin{array}{l}\text { Profesionales (nivel bajo), } \\
\text { altos administrativos y } \\
\text { propietarios de comercio }\end{array}$} & $2,4 \%$ & $3,9 \%$ & $3,0 \%$ \\
\hline 5 & \multicolumn{2}{|c|}{$\begin{array}{c}\text { Administrativos y } \\
\text { vendedores (nivel bajo) }\end{array}$} & $2,4 \%$ & $7,8 \%$ & $4,7 \%$ \\
\hline 7 y 9 & \multicolumn{2}{|c|}{$\begin{array}{l}\text { Trabajadores industriales } \\
\text { semi y bajo cualificados }\end{array}$} & $8,7 \%$ & $5,8 \%$ & $7,3 \%$ \\
\hline 10 & $\begin{array}{c}\text { Trabajadores } \\
\text { no cualificados } \\
\text { del sector } \\
\text { primario }\end{array}$ & $\begin{array}{l}\text { Pescador, } \\
\text { altura, } \\
\text { bajura y } \\
\text { fluvial }\end{array}$ & $12,6 \%$ & $13,6 \%$ & $12,8 \%$ \\
\hline \multirow[t]{3}{*}{11} & \multirow{3}{*}{$\begin{array}{l}\text { Trabajadores } \\
\text { de la industria } \\
\text { y el transporte } \\
\text { no cualificados }\end{array}$} & $\begin{array}{l}\text { Marinero, } \\
\text { ordinario o } \\
\text { de primera }\end{array}$ & $15,0 \%$ & $29,1 \%$ & $20,9 \%$ \\
\hline & & Peón & $0,0 \%$ & $1,0 \%$ & $0,4 \%$ \\
\hline & & Total & $15,0 \%$ & $30,1 \%$ & $21,4 \%$ \\
\hline \multirow{4}{*}{-9} & \multirow{4}{*}{$\begin{array}{l}\text { Trabajadores } \\
\text { y jornaleros }\end{array}$} & Trabajador & $0,8 \%$ & $0,0 \%$ & $0,4 \%$ \\
\hline & & Jornalero & $48,0 \%$ & $27,2 \%$ & $38,9 \%$ \\
\hline & & $\begin{array}{c}\text { Ocupación } \\
\text { demasiado } \\
\text { vaga o } \\
\text { referida a } \\
\text { multitud de } \\
\text { actividades } \\
\text { ocupacional } \\
\text { es }\end{array}$ & $2,4 \%$ & $7,8 \%$ & $4,7 \%$ \\
\hline & & Total & $51,2 \%$ & $35,0 \%$ & $44,0 \%$ \\
\hline \multirow[t]{2}{*}{-1} & \multicolumn{2}{|c|}{$\begin{array}{l}\text { Sin profesión o sin } \\
\text { profesión conocida }\end{array}$} & $7,9 \%$ & $3,9 \%$ & $6,8 \%$ \\
\hline & \multicolumn{2}{|l|}{ Total casos } & 127 & 103 & 230 \\
\hline
\end{tabular}

Fuente: Elaboración propia a partir de la muestra del Padrón Municipal de Habitantes de Barcelona, 1930

No es de extrañar el elevado porcentaje de hombres dedicados a actividades marítimas -ya fueran la pesca, la marinería o los trabajos portuarios- si tenemos en cuenta que la gran mayoría de ellos, el $82 \%$, procedía de alguna ciudad costera (Mapa 7). Sus procesos de inmigración deben, pues, vincularse directamen- 
te a la aguda crisis pesquera que se produjo en la segunda mitad del siglo XIX en todo el litoral valenciano (Viruela, 1995a). Además, algunas ciudades como Torrevieja o Benicarló - con una gran importancia en nuestros datos- padecieron desde finales de 1870 continuas epidemias de cólera, la caída de los precios de sus principales productos de exportación y, más tarde, sobre todo tras la I Guerra Mundial, una importante regresión del comercio marítimo (Viruela, 1995b: 155). Dentro de la capital catalana, la Barceloneta y el puerto constituían el mercado laboral idóneo que les proporcionaba mejores oportunidades laborales, para las que contaban con preparación y experiencia. Seguramente disponían también de una red de paisanaje que les facilitaba el acceso a ese nicho laboral, así como la integración a las redes de sociabilidad en el barrio tanto para ellos como para sus familias. ${ }^{42}$ Esta integración, asimismo, podía haber estado facilitada por el uso de la lengua catalana. Si bien no podemos determinar qué idioma materno era el de estos inmigrantes al no costar en el padrón, sí que podemos inferir que el hecho de proceder mayoritariamente de zonas costeras, históricamente valencianohablantes -incluso en el caso de Morella, un núcleo del interior bien presente en nuestros datos, pero también tradicionalmente valencianohablante-, significaría que estos inmigrantes hablarían el valenciano. Este hecho podría haber facilitado su integración, sociabilidad y el acceso a mejores oportunidades laborales (dentro de los grupos de media-baja cualificación) que las de otros inmigrantes castellanohablantes del entorno.

Aunque, como hemos visto, el colectivo valenciano en la Barceloneta se ocupaba en trabajos situados en los sectores bajos de la escala laboral, hay que destacar que, entre los que llegaron tras el inicio de la I Guerra Mundial el porcentaje de trabajadores de oficinas y del comercio (grupos 4 y 5 , especialmente el segundo) era ligeramente mayor que entre quienes se habían instalado con anterioridad. El porcentaje, en cambio, de trabajadores industriales semicualificados era menor entre los que llegaron más tarde. Además, mientras que de los que llegaron antes de 1914 un $27 \%$ se declaró pescador o marinero y un $48 \%$ jornalero, de los que llegaron posteriormente se declaró marinero o pescador un $43 \%$ y jornalero un $27 \%$. Este cambio, la mayor dedicación a las actividades marítimas y la menor al peonaje, se produce sin que se constate un

\footnotetext{
${ }^{42}$ En el caso, por ejemplo, de los pescadores de la Barceloneta, parece que el grado de endogamia matrimonial dentro del oficio podía ser elevado. Así, entre un colectivo de familias de trabajadoras metalúrgicas que residían en la Barceloneta entre 1930 y 1950, la mayoría de las cuales era de origen inmigrante andaluz, prácticamente la mitad de las que tenían un padre pescador se casó con un pescador, un fenómeno que no se daba entre las que tenían padres con otras ocupaciones (Villar, 2013).
} 


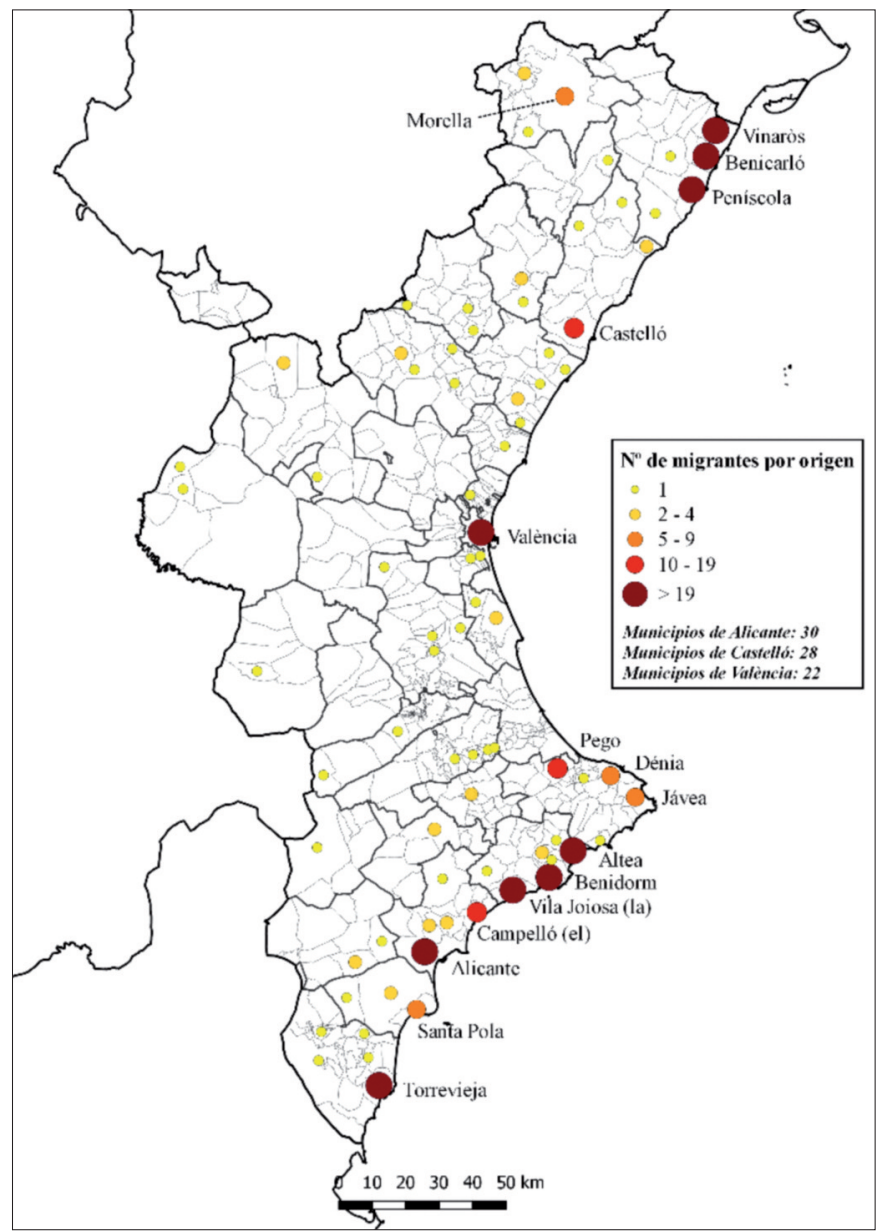

Mapa 7. Origen de la inmigración valenciana, la Barceloneta, 1930 Fuente: Elaboración propia a partir de la muestra del Padrón Municipal de Habitantes de Barcelona, 1930

aumento de las llegadas de municipios costeros tras 1914 (que se mantuvieron en torno al 80\%) y, en un momento en el que el sector pesquero valenciano estaba en recuperación tras la grave crisis del siglo XIX (Viruela, 1995a). Esto apunta a que, con el tiempo, el flujo migratorio desde el País Valenciano se debió menos a factores de expulsión -la crisis de la pesca- y más a factores de atracción -el crecimiento de Barcelona, el efecto llamada de parientes y paisanos, etcétera-. Puede decirse que el análisis de las ocupaciones no señala la existen- 
cia de un perfil más proletario de la inmigración valenciana masculina tras 1914, sino más bien todo lo contrario, un ligero aumento de la cualificación, aunque, eso sí, sin moverse dentro de los sectores bajos de la escala sociolaboral.

En el mismo sentido apuntan los datos sobre alfabetización. Es cierto que la población valenciana en la Barceloneta presenta tasas de alfabetización menores a las existentes en la ciudad de Barcelona en 1930. Mientras que el 81\% de los barceloneses y el $72 \%$ de las barcelonesas estaban alfabetizados en $1930,{ }^{43}$ estas cifras se reducían a un $64 \%$ de los hombres y a un $49 \%$ de las mujeres en el caso del colectivo valenciano en la Barceloneta. Sin embargo, también es cierto que constituía un grupo mucho más instruido que el conjunto de la población residente en el País Valenciano (Tabla 6). Entre los que llegaron a la Barceloneta hasta 1914, el 60\% de los valencianos y el $41 \%$ de las valencianas sabían leer y escribir mientras que, en origen, para 1910, lo hacía apenas el 35\% de los hombres y el 22\% de las mujeres. Las mismas diferencias se observan entre los que llegaron a Barcelona tras el inicio de la I Guerra Mundial. Así, aunque la tasa de alfabetización en origen aumentó a lo largo del primer tercio del siglo XX, también lo hizo entre los inmigrantes en la Barceloneta que llegaron tras 1914 a la ciudad y alcanzó el 72\% entre los hombres y el 58\% entre las mujeres. Además, si tenemos en cuenta el origen provincial, se observa como los inmigrantes de la provincia de Alicante, que son los que llegaron masivamente a partir de 1911, estaban más alfabetizados que el resto de sus paisanos. Un $62 \%$ de la inmigración alicantina estaba alfabetizada, mientras que la valenciana y la castellonense lo estaba en un 54\% y $45 \%$ respectivamente. Por tanto, en consonancia con la tendencia al alza de las tasas de alfabetización en origen, en general la inmigración valenciana que llegó a la Barceloneta -y de las cual aproximadamente un tercio pudo escolarizarse en Barcelona, ya que llegó antes de los 14 años- estaba cada vez más instruida, lo que apunta claramente a una emigración positivamente seleccionada.

En definitiva, el análisis de la ocupación indica que la inmigración valenciana residente en la Barceloneta se ocupaba en 1930 en los peldaños inferiores de la escala laboral y eso no variaba de forma sustancial en función del tiempo de residencia en la ciudad. Sí parece, sin embargo, que el flujo inmigratorio valenciano -al menos el procedente de zonas costeras- cada vez respondió más a la atracción que ejercía Barcelona que a la expulsión provocada por la crisis de la pesca en los lugares de origen, por cuanto esta se fue mitigando. Esta atracción alcanzó cada vez estratos de población mejor posicionados, más familias dedicadas al ámbito de la pesca y la marinería y, como hemos visto, en estadios más avanzados de su ciclo vital, con más miembros en edad

\footnotetext{
${ }^{43}$ De acuerdo con los datos del Censo Nacional de Población de ese año.
} 
Tabla. 6 Alfabetización de la inmigración valenciana en la Barceloneta según el momento de llegada a la ciudad (Barcelona, 1930) y de la población residente en sus provincias de origen, 1900-1930

\begin{tabular}{|c|c|c|c|c|c|c|c|c|c|c|c|c|}
\hline \multicolumn{13}{|c|}{ En provincia de origen } \\
\hline \multirow[t]{2}{*}{ Año } & \multicolumn{3}{|c|}{ Alic ante } & \multicolumn{3}{|c|}{ Castelló } & \multicolumn{3}{|c|}{ València } & \multicolumn{3}{|c|}{ Total casos } \\
\hline & Hombre & Mujer & Total & Hombre & Mujer & Total & Hombre & Mujer & Total & Hombre & Mujer & Total \\
\hline 1900 & $27 \%$ & $16 \%$ & $22 \%$ & $27 \%$ & $14 \%$ & $21 \%$ & $33 \%$ & $19 \%$ & $26 \%$ & $30 \%$ & $17 \%$ & $24 \%$ \\
\hline 1910 & $34 \%$ & $22 \%$ & $28 \%$ & $34 \%$ & $20 \%$ & $27 \%$ & $36 \%$ & $23 \%$ & $30 \%$ & $35 \%$ & $22 \%$ & $29 \%$ \\
\hline 1920 & $44 \%$ & $32 \%$ & $38 \%$ & $43 \%$ & $29 \%$ & $36 \%$ & $49 \%$ & $38 \%$ & $44 \%$ & $47 \%$ & $34 \%$ & $40 \%$ \\
\hline 1930 & $54 \%$ & $41 \%$ & $47 \%$ & $55 \%$ & $40 \%$ & $47 \%$ & $59 \%$ & $47 \%$ & $53 \%$ & $57 \%$ & $44 \%$ & $51 \%$ \\
\hline \multicolumn{13}{|c|}{ Residentes en la Barceloneta* } \\
\hline Llegada a & \multicolumn{3}{|c|}{ Alicante } & \multicolumn{3}{|c|}{ Castelló } & \multicolumn{3}{|c|}{ València } & \multicolumn{3}{|c|}{ Total casos } \\
\hline Barcelona & Hombre & Mujer & Total & Hombre & Mujer & Total & Hombre & Mujer & Total & Hombre & Mujer & Total \\
\hline Hasta 1914 & $70 \%$ & $46 \%$ & $59 \%$ & $47 \%$ & $28 \%$ & $36 \%$ & $42 \%$ & $55 \%$ & $50 \%$ & $61 \%$ & $41 \%$ & $50 \%$ \\
\hline Desde 1915 & $66 \%$ & $63 \%$ & $65 \%$ & $67 \%$ & $53 \%$ & $59 \%$ & $88 \%$ & $40 \%$ & $61 \%$ & $72 \%$ & $58 \%$ & $63 \%$ \\
\hline Total casos & $68 \%$ & $55 \%$ & $62 \%$ & $55 \%$ & $38 \%$ & $45 \%$ & $60 \%$ & $50 \%$ & $54 \%$ & $64 \%$ & $49 \%$ & $56 \%$ \\
\hline
\end{tabular}

* Se ha observado el dato de alfabetización en las declaraciones de la población mayor de 11 años. Se han considerado población alfabetizada aquella que declaró que sabía leer y escribir.

Fuente: Elaboración propia a partir de los datos de los Censos Nacionales de Población, 1900-1930 y de la muestra del Padrón Municipal de Habitantes de Barcelona, 1930

de trabajar, que llegaron a la ciudad tras el inicio de la guerra mundial, un poderoso acicate para el desarrollo industrial y comercial de Barcelona. El aumento de los niveles de alfabetización de quienes llegaron a partir de ese momento, tanto entre los hombres como entre las mujeres, refuerza la idea de que la inmigración valenciana, lejos de experimentar un cambio a peor en su status sociolaboral, constituyó cada vez más un colectivo positivamente seleccionado en origen que buscaba ampliar en la capital catalana sus perspectivas de mejora social. Con todo, es conveniente que analicemos otros indicadores que nos permitan medir, más allá del ámbito laboral, el nivel de integración social de estos/as inmigrantes y sus familias.

\section{Los hogares}

Por último, ¿de qué manera vivían estos valencianos? ¿Con quién convivían? Son preguntas que contribuyen a valorar el nivel de integración que habían alcanzado en la ciudad. En primer lugar, al analizar el tamaño de sus hogares, 
llama la atención la enorme coincidencia con el del conjunto de Barcelona; 4,42 personas por hogar. Esta cifra, ligeramente inferior a la que arrojaban los hogares encabezados mayoritariamente por hombres valencianos en la ciudad (Oyón et al., 2001) de 4,84, está muy por debajo de los 5,16 miembros que tenían de promedio los hogares de otros colectivos inmigrantes, con mayoría de andaluces, que también residían en la Barceloneta en 1930 (Villar, 2013: 239). Está también por debajo del número de miembros por hogar del resto de grupos inmigrantes analizados para toda Barcelona (Oyón et al., 2001). ${ }^{44}$ Es decir, estas familias valencianas distaban mucho de vivir en las condiciones de hacinamiento en las que lo hacía el sector más pobre de la clase jornalera inmigrante, incluso de la que residía en el mismo barrio.

Con el 26,8\% de los hogares analizados con la forma de familia extensacompleja (hogares tipo 4 y 5 , véase la Tabla 7), ya se puede hablar de un ligero predominio de este tipo de hogar (Laslett, 1983) y, dentro de esta, de la familia troncal, lo que no es extraño, ya que este tipo de hogar se da también en el caso de muchos inmigrantes en los que la emigración se produce en familia. Es decir, los mayores llegaron con sus padres y madres y los jóvenes llegaron con sus hijos y se mantuvieron en familia. Por tanto, al igual que en otros casos de inmigración familiar analizada en la Barceloneta, concretamente la andaluza (Villar, 2013), no puede decirse que la emigración comportara desarraigo familiar. Sin embargo, en el caso de estas familias valencianas, seguramente no sería tanto por las dificultades para emanciparse -aunque en este sentido hay que recordar la carga que suponía en la Barcelona de 1930 el alquiler para el presupuesto de la clase obrera- ${ }^{45}$ Serían en este caso más bien las dificultades para las personas mayores de mantenerse solas las que contribuirían a mantener la familia troncal. Y lo sería especialmente en el caso de las mujeres, que son la mayoría de las que recurrían al hospedaje cuando no convivían con familiares. Tanto si era por cuestiones económicas como por motivos culturales, se mantenía la costumbre de que fuera una de las hijas quien se quedase en el hogar familiar para hacerse cargo de los padres, tal como indica la mayor presencia de suegros y suegras en los hogares, mientras el resto de los hermanos lo abandonan a medida que contraen matrimonio. Es por eso que la forma exten-

${ }^{44}$ Por ejemplo, en el conjunto de Barcelona los andaluces o almerienses vivían en hogares de un tamaño medio de 5,53 y 6,04 miembros respectivamente. Incluso en el caso de los aragoneses, cuyo tamaño de hogar era el más pequeño de todos los grupos inmigrantes analizados por Oyón et al. (2001), su tamaño era mayor que en nuestra muestra de hogares.

${ }^{45}$ Barcelona tenía uno de los alquileres más caros de Europa, hasta el punto de representar entre un 30\% y 40\% del salario obrero (Oyón, 2008), lo que llegó a ocasionar una huelga de alquileres y la creación de un sindicato para defender a los inquilinos: el Comité de Defensa Económica (Ealham, 2005; Aisa, 2014). 
Tabla 7. Tipos de hogar de la inmigración valenciana en la Barceloneta, Barcelona, 1930 46

\begin{tabular}{|c|c|c|c|}
\hline \multicolumn{2}{|c|}{ Tipo de hogar } & \multirow{2}{*}{$\begin{array}{c}\mathbf{\%} \\
3,2 \%\end{array}$} & \multirow{2}{*}{$\begin{array}{c}\text { \% huéspedes } \\
62,5 \%\end{array}$} \\
\hline Solitario-no familia (tipo 1-2) & Viudos/viudas & & \\
\hline & $\begin{array}{c}\text { Solteros/solteras o EC } \\
\text { desconocido }\end{array}$ & $0,8 \%$ & $50,0 \%$ \\
\hline & Hermanos/hermanas & $0,4 \%$ & $0,0 \%$ \\
\hline & Otros parientes & $0,4 \%$ & $0,0 \%$ \\
\hline Total tipo 1-2 & & $4,7 \%$ & $50,0 \%$ \\
\hline \multirow[t]{4}{*}{ Familias simples (tipo 3) } & Parejas sin hijo(s) & $12,6 \%$ & $21,9 \%$ \\
\hline & Parejas con hijo(s) & $48,4 \%$ & $8,1 \%$ \\
\hline & Padre con hijo(s) & $2,4 \%$ & $16,7 \%$ \\
\hline & Madre con hijo(s) & $5,1 \%$ & $15,4 \%$ \\
\hline Total tipo 3 & & $68,5 \%$ & $11,5 \%$ \\
\hline \multirow[t]{3}{*}{ Familias extensas (tipo 4) } & Con ascedente(s) & $11,4 \%$ & $0,0 \%$ \\
\hline & Con descendente(s) & $0,8 \%$ & $0,0 \%$ \\
\hline & Con colateral (es) & $3,5 \%$ & $0,0 \%$ \\
\hline Total tipo 4 & & $15,8 \%$ & $0,0 \%$ \\
\hline \multirow[t]{5}{*}{ Familias multiples (tipo 5) } & $\begin{array}{l}\text { Nucleo secundario } \\
\text { ascendente }\end{array}$ & $1,6 \%$ & $0,0 \%$ \\
\hline & $\begin{array}{l}\text { Nucleo secundario } \\
\text { descendente }\end{array}$ & $6,3 \%$ & $0,0 \%$ \\
\hline & $\begin{array}{l}\text { Nucleos colaterales }+ \\
\text { miembro(s) generación } \\
\text { anterior }\end{array}$ & $0,4 \%$ & $0,0 \%$ \\
\hline & $\begin{array}{c}\text { Nucleos colaterales sin } \\
\text { miembro(s) generación } \\
\text { anterior }\end{array}$ & $0,8 \%$ & $0,0 \%$ \\
\hline & $\begin{array}{l}\text { Otras combinaciones } \\
\text { Indeterminados }\end{array}$ & $\begin{array}{l}0,8 \% \\
1,2 \%\end{array}$ & $\begin{array}{c}0,0 \% \\
33,3 \%\end{array}$ \\
\hline Total tipo 5 & & $11,0 \%$ & $3,6 \%$ \\
\hline Total casos & & 254 & 10,6 \\
\hline
\end{tabular}

Fuente: Elaboración propia a partir de la muestra del Padrón Municipal de Habitantes de Barcelona, 1930

\footnotetext{
${ }^{46}$ Clasificación determinada en Laslett (1983).
} 
sa-compleja es más frecuente en la fase inicial -de recién casados cuando todavía viven los padres- y en la fase final -cuando se casan los hijos- lo que indica que, si bien la mayor parte de las parejas se emancipaban al contraer matrimonio, había un buen número de parejas que no lo hacía.

Estos matrimonios estaban formados mayoritariamente por parejas en la que ambos cónyuges eran valencianos. De esta manera, hasta un $71 \%$ y un $70 \%$ de los cabezas de familias varones y mujeres que estaban casados lo estaban con una valenciana y un valenciano respectivamente, mientras que los que se casaron con una barcelonesa o barcelonés lo estaban en porcentajes de tan solo un $16 \%$ y $13 \%$ respectivamente. Dentro de estos hogares, además, el menor porcentaje de nacidos en la Comunidad Valenciana en los hermanos (50\%) pero el mayor en los cuñados (72\%) indica, por un lado, que la llegada de esta generación se produjo en parte como consecuencia del proceso migratorio de la generación anterior -también en los primeros estadios del ciclo familiar-. Por otro lado, indica también el elevado grado de homogamia territorial de las primeras familias que llegaron a Barcelona, cuyos miembros, aun habiendo nacido ya en Barcelona, se casaron mayoritariamente con valencianos. Dicha homogamia, aunque disminuyó en la generación posterior, se mantuvo elevada: el $56 \%$ de los yernos y nueras son valencianos, aun cuando casi el $65 \%$ de los hijos de estas familias había nacido en Barcelona (Tabla 9). Todo esto apunta, por tanto, a la importancia de las redes de sociabilidad sostenidas por el paisanaje en el ámbito más cercano del barrio, que, en el caso de la Barceloneta, con un importantísimo tejido industrial y de servicio maritimoportuario, es también donde se ejerce la actividad laboral y, en muchos casos, donde se tejen las relaciones amorosas. Igual de importante parece el paisanaje cuando se trata de compartir el espacio personal, ya que, del conjunto de parientes sin determinar el grado, huéspedes u otro tipo de personas alojadas en los hogares, el 52\% habría nacido en el País Valenciano, por un 30\% en Barcelona capital (Tabla 8).

\section{A modo de conclusión}

El objetivo de este artículo ha sido analizar la integración de la inmigración valenciana en la ciudad de Barcelona y, así, contrastar si, como se ha considerado para el conjunto de la inmigración en la capital catalana, este colectivo perdió capacidad de integración y en qué condiciones se produjo dicho proceso. Para ello, hemos analizado la distribución de la inmigración valenciana en el espacio de la ciudad, identificando importantes zonas de concentración como ya hicieron otros autores (Oyón et al., 2001), pero también descubriendo otras donde se consideró que su presencia era prácticamente nula. De esta 


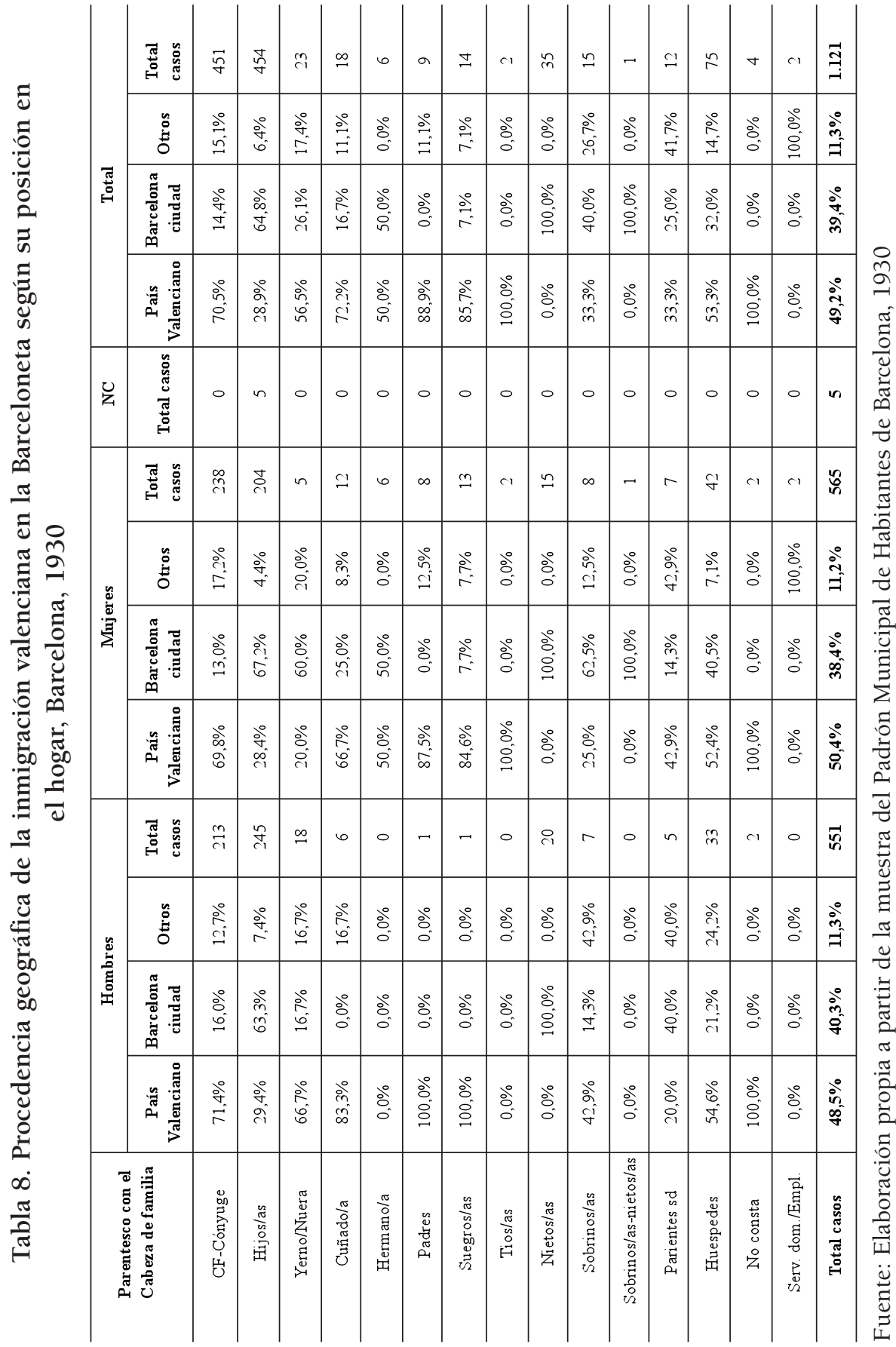


manera, en determinados barrios de la Esquerra y Dreta de l'Eixample, así como en Sagrada Familia, Guinardó y Camp de l'Arpa se ha puesto de relieve el importante papel numérico que tenía la inmigración valenciana, con más de 1.000 valencianos por barrio, o incluso en determinadas zonas de Gràcia, con más de 500. Asimismo, se ha evidenciado la importantísima presencia de la inmigración femenina valenciana en zonas que hasta ahora habían pasado desapercibidas. Esta inmigración, cuyas características específicas habrá que analizar en profundidad en un futuro, estaba situada mayoritariamente en la Barcelona más bienestante y debe relacionarse con un mercado de trabajo altamente demandante de mano de obra femenina -el servicio doméstico y el clero-, pero también con zonas de predominio de un proletariado industrial femenino, como Sant Andreu y la Sagrera, donde se ubicaban algunas grandes fábricas textiles.

El análisis de la inmigración valenciana en el barrio de la Barceloneta nos habla de un colectivo que constituyó una comunidad que, aunque bien integrada socialmente en comparación con otros colectivos inmigrantes del barrio, mantuvo fuertes lazos de paisanaje. La inmigración valenciana de la Barceloneta constituía un grupo de gente joven, que había emigrado mayoritariamente en familia, concretamente en los primeros estadios del ciclo familiar, y que se instaló en el barrio que les ofrecía mayores oportunidades laborales de acuerdo con sus cualificaciones, relacionadas con las actividades maritimopesqueras obtenidas en el lugar de origen. Predominaba ligeramente la familia extensa, aunque el tamaño medio del hogar era inferior al de otros grupos migrantes de la época, como los andaluces, y, de hecho, era exactamente igual que el de la media de hogares barceloneses. Esto indica una adaptación a las pautas demográficas y residenciales de Barcelona, incluso también en los estratos socioeconómicos inferiores ya que, solo en casos excepcionales, los hogares con valencianos tenían que recurrir al subarrendamiento u hospedaje. Igualmente, podemos considerar que no hubo desarraigo familiar ni social dada la importancia de la familia extensa-múltiple y el elevado nivel de homogamia geográfica. Y es que los valencianos y las valencianas de la Barceloneta se casaron con miembros de sus zonas de procedencia e incluso sus hijos e hijas ya nacidos en Barcelona hicieron lo propio en la mayoría de los casos.

Una de las principales conclusiones que podemos apuntar es que no hay ningún indicio de empeoramiento en las condiciones de integración de estos inmigrantes. Primero, porque conforme pasó el tiempo los inmigrantes que llegaron estaban más cualificados. Segundo, porque no se produjo un aumento de la ocupación como jornalero, sino todo lo contrario: los llegados a partir de 1914 se integraron, sobre todo, como pescadores o marineros. Tercero, porque el ta- 
maño medio de los hogares, un indicador del nivel de bienestar y adaptación, sigue la pauta del conjunto de la ciudad y se situaba muy por debajo de otros colectivos inmigrantes que, con menores niveles de cualificación, vivían en la Barceloneta en condiciones de hacinamiento y pobreza que estas familias valencianas no presentan. Y en cuarto y último lugar, y como algo que queda para una futura investigación, cabe plantear la posibilidad de que el uso del catalán facilitara su integración respecto a otros grupos de inmigrantes castellanoparlantes de la época, ya que, de hecho, la mayoría de estos migrantes vinieron de zonas valencianoparlantes.

\section{Bibliografía}

AGULLÓ, Victor (2011). Los valencianos en Uruguay. Valencia: Generalitat Valenciana, Conselleria de Solidaridad y Ciudadanía.

AISA, Manel (2014). La huelga de alquileres y el comité de defensa económica. Barcelona: El Lokal.

ALAPONT, Maria José (2013). Moviments migratoris: valencians a Nova York. Clapir, Joves Historiadors i Historiadores Valencians. <http:/hystoryuv.webcindario.com/va lencians-novayork.pdf>

ALEGRET, José Luis; GARRIDO, Alfons (2008). Historia del puerto pesquero de Palamós: migraciones, asociacionismo y desarrollo. Areas. Revista Internacional de Ciencias Sociales, 27, 27-40. <http://revistas.um.es/areas/article/view/118601/ 111901>

ALONSO, Maria del Carmen (2010). Los valencianos en Buenos Aires. Historia, identidad y lengua. Paiporta: Editorial Denes S.L.

ARANGO, Joaquín (1976). Cambio económico y movimientos migratorios en la España oriental del primer tercio del siglo XX: algunas hipótesis sobre determinantes y consecuencias. Hacienda Pública Española, 38, 51-80.

ARANGO, Joaquín (2007). Les primeres migracions del segle XX a Catalunya. Nadala 2007, any 41, 19-33.

ARBAIZA, Mercedes (1998). Labor migration during the first phase of Basque industrialization: The labor market and family motivations. The History of the Family, 3(2), 199-219. <https://s3.amazonaws.com/academia.edu.documents/44694781/ 14.Labor_Migration._Journal_of_FamiyHist.1998.pdf?AWSAccessKeyId=AKIAIWOWYYGZ2Y53UL3A\&Expires $=1525696973 \&$ Signature $=$ TCTN98\%2FfaKWin 5hAdXZ\%2Br\%2FtauFM\%3D\&response-content-disposition=inline $\% 3 \mathrm{~B} \% 20$ file name\%3DLabor_migration_during_the_first_phase_o.pdf>

AZAGRA, Joaquín; CHORÉN, Pilar; GOERLICH, Francisco J; MÁS, Matilde (2006). La localización de la población española sobre el territorio: un siglo de cambios: un estudio basado en series homogéneas (1900-2001). Bilbao: Fundacion BBVA. < https:// www.fbbva.es/wp-content/uploads/2017/05/dat/DE_2006_IVIE_localizacion_ poblacion_espanola.pdf> 
BALCELLS, Albert (2015). La immigració i la política catalana durant la Segona República. Cercles: revista d'història cultural, (18), 21-41. <https://www.raco.cat/index. php/Cercles/article/view/298910>

BAILA, Miquel A. (1994). El paper de València en la transició demogràfica al País Valencià (1860-1930). Cuadernos de Geografía, 55, 27-44.

BELCHEM, John (1999). The Liverpool Irish enclave. Immigrants \& Minorities: Historical Studies in Ethnicity, Migration and Diaspora, 18:2-3, 128-146. <https://doi.org/10.1080/02619288.1999.9974971>

BELTRAN, Vicent; SEGURA-LLOPES, Carles (2017). Els parlars valencians. València: Universitat de València.

BONMATÍ, José Fermín (1989). La emigración alicantina a Argelia: siglo XIX y primer tercio del siglo XX. Alicante: Universidad de Alicante.

BORDERÍAS, Cristina; GONZÁLEZ, Roser; VILLAR, Conchi (2011) El trabajo femenino en la Cataluña industrial (1919-1930): una propuesta de reconstrucción. Revista de Demografía Histórica, 29 (1), 55-88.

BORRELL, Mònica (2015) El servei domèstic a la ciutat de Barcelona, 1900-1950. Tesis doctoral, Universitat de Barcelona, Departament d'Història Contemporània. <https://www.tdx.cat/handle/10803/394073>

CAMPS, Enriqueta (1995). La formación del mercado de trabajo industrial en la Cataluña del siglo XIX. Madrid: Ministerio de Trabajo y Seguridad Social.

CABRÉ, Anna. (1999). El sistema català de reproducció. Proa.

CAMPMANY, Josep (2015). L'impacte associatiu i cultural de la immigració valenciana a Gavà. Els moviments migratoris a les terres d'Eramprunyà, Antic escorxador. Begues, 14 de novembre de 2015, Actes. <http://centredestudis.gava.ppe.entitats. diba.cat/wp-content/uploads/sites/10/2016/01/Ponencia-Gava-VIII-Trobades2015.pdf>

CARBALLO, Borja (2011). El perfil profesional de la población madrileña entre 1860 y 1900. En Arantza PAREJA (dir.). El capital humano en el mundo urbano: experiencias desde los padrones municipales (1850-1930) (75-100). Universidad del País Vasco/Euskal Herriko Unibertsitatea.

CARNERO, Teresa (1978). Crisi i burgesia conservadora durant la Gran Depressió: el País Valencià, 1879-1889. Estudis d'història agrària, 1, 98-113. <http://www.raco.cat/ index.php/EHA/article/view/99502/145498>

OTERO, Luis Enrique; PALLOL, Rubén (2009). El Madrid moderno, capital de una España urbana en transformación, 1860-1931. Historia contemporánea, 39, 541588. < http://www.ehu.eus/ojs/index.php/HC/article/view/2380/1980>

CHECA, Martí (1997) Les estacions ferroviàries i el desenvolupament industrial i urbà. El cas de la Sagrera (Barcelona). Actas de las IV Jornades d'Arqueologia Industrial de Catalunya. Barcelona, noviembre de 1997.

CHECA, Martí (1999). Immigrants, jornalers i colonitzadors: el barri de la Trinitat Vella, Barcelona (1921-1936). Finestrelles, 10, 79-93.

<http://www.raco.cat/index.php/Finestrelles/article/view/214557> 
CORTIZO, Tomas (1983). Flujos y cambios migratorios en España en 1920. Ería: Revista cuatrimestral de geografía, 5, 117-132. <https://dialnet.unirioja.es/descarga/ articulo/858295.pdf>

DOHERTY, John (1985). Short-distance migration in Mid-Victorian Lancashire: Blackburn and Bolton 1851-71. Tesis doctoral, Universidad de Lancaster.

DOMINGO, Andreu (2012). Immigració i política demogràfica a l'obra de Josep Antoni Vandellós. Treballs de la Societat Catalana de Geografia, 73, 9-26. $<$ http://dx.doi.org/10.2436/20.3002.01.1>

DOMINGO, Andreu; PITARCH, Kenneth (2015). La Població valenciana a Catalunya al segle XXI: anàlisi demogràfica i espacial. Treballs de la Societat Catalana de Geografia, 79, 9-37. <http://dx.doi.org/10.2436/20.3002.01.77>

EALHAM, Chris (2005). Class, culture and conflict in Barcelona, 1898-1937. London $\&$ New York: Routledge.

EGEA, Pedro María (1984). La clase obrera de Alcoy a finales del siglo XIX. Anales de Historia Contemporánea, 3, 123-158. <http://revistas.um.es/analeshc/article/view/ 106291/101091>

FERNÁNDEZ, Juan José (1991). Incidencia en la población del País Valenciano del cólera de 1885. Actas del II Congreso de la Asociación de Demografía Histórica. Alicante, abril de 1990 (81-88). Seminari d" Estudis sobre la Població del País Valencià.

FIELDING, Steven (1992). Class and Ethnicity: Irish Catholics in England, 1880-1939. Philadelphia: Open University Press.

FIGUERES, Xavier (2017). Quan la mar brama. Publicacions URV.

FOLGUERÀ, Stella Maris (1997). Arroz Viudo y Papas Pobres. Blasco Ibáñez y la Nueva Valencia en Argentina. Simat de la Valldigna: Ed. La Xara.

FURIÓ, Antoni (2001). Història del País Valencià. València: Edicions 3 i 4.

GALLARDO, Juan José; OYÓN, José Luis (2004). El cinturón rojinegro: radicalismo cenetista y obrerismo en la periferia de Barcelona (1918-1939). Ediciones Carena.

GARCÍA, Rocío (2005). Emigrar a la ría de Bilbao. Factores de expulsión y selección del capital humano en la emigración a la Ría de Bilbao (1877-1935). Bilbao: Universidad del País Vasco

GONZÁLEZ, Manuel (ed.) (2001). Los origenes del área metropolitana de la Ría de Bilbao. Bilbao: Fundación BBVA.

GONZÁLEZ, Manuel; GARCÍA, Rocío; ZARRAGA, Karmele (2011). La zonificación social de la Ría de Bilbao (1876-1930). En Arantza PAREJA (dir.). El capital humano en el mundo urbano: experiencias desde los padrones municipales (1850-1930) (1544). Universidad del País Vasco/Euskal Herriko Unibertsitatea.

GUILLAMON, Julià (2018). El barri de la Plata. Barcelona: L'Avenç.

HAREVEN, Tamara K. (1993). Family time and industrial time: The relationship between the family and work in a New England Industrial Community. New York: University Press of America. 
HATTON, Timothy J.; BAILEY, Roy E. (2002). Natives and migrants in the London labour market, 1929-1931. Journal of Population Economics, 15(1), 59-81.

<http://www.jstor.org/stable/20007800>

HUMPHRIES, Jane; SARASÚA, Carmen (2012). Off the record: Reconstructing women's labor force participation in the European past. Feminist Economics, 18 (4), 39-67.

IBARZ, Jordi (2003). Oficios y cualificaciones en el trabajo portuario. El caso de Barcelona en la primera mitad del siglo XX. Historia social, 45, 119-137.

<http://www.jstor.org/stable/40340847>

IBARZ, Jordi (2008). Building skills_the case of Barcelona's dockers in the 20th century. Labour specialization and residence guidelines on the 30s. <https://www.academia. edu/32181129/BUILDING_SKILLS_THE_CASE_OF_BARCELONAS_DOCKERS_ IN_THE_20th_CENTURY._LABOUR_SPECIALIZATION_AND_RESIDENCE_ GUIDELINES_ON_THE_30s>

IBARZ, Jordi (2010). Migration in the Formation of the Labour Market in the Barcelona Docks (1910-1947). Journal of Mediterranean Studies, 19(2), 271-293. <https://muse.jhu.edu/article/673528/pdf>

KOCKA, Jürgen (1986). Problems of Working-Class Formation in Germany: The Early Years, 1800-1875. En Ira KATZNELSON; Aristide R. ZOLBERG (eds.). Working-class formation: nineteenth-century patterns in Western Europe and the United States, (279-351). Princenton: Princenton University Press.

LASLETT, Peter (1983). The world we have lost: further explored. London: Methuen.

LEE, William R.; MARSCHALCK, Peter (2000). Demographic change and industrialization in germany, 1815-1914: Bremen in Comparative Perspective. The History of the Family, 5(4), 373-390. https://doi.org/10.1016/S1081-602X(00)00051-8

LLONCH, Montserrat (1994). Inserción laboral de la inmigración y sistema de reclutamiento de la fábrica textil: Vilassar de Dalt, 1919-1945. Revista de Demografía Histórica, 12(2), 149-162.

LLORCA, Francesc Xavier (2000). El llenguatge mariner de la Marina. San Vicente del Raspeig: Publicaciones de la Universidad de Alicante. <http://www.museudela pesca.org/docs/unitats/lenguatge/llenguatge_mariner.pdf>

LONG, Jason (2005). Rural-urban migration and socioeconomic mobility in Victorian Britain. The Journal of Economic History, 65(1), 1-35. <http://www.jstor.org/stable/ 3875041>

LÓPEZ, Pilar (2004). Naturales e inmigrantes en Barcelona a mediados del siglo XIX. Barcelona quaderns d'història, 11, 69-92. <http://www.raco.cat/index.php/BCN Quaderns Historia/article/view/105586>

LÓPEZ-GAY, Antonio (2008). Canvis residencials i moviments migratoris en la renovació poblacional de Barcelona. Barcelona: CTESC.

LÓPEZ-GAY, Antonio (2014). 175 años de series demográficas en la ciudad de Barcelona. La migración como componente explicativo de la evolución de la población. Biblio 3W. Revista Bibliográfica de Geografía y Ciencias Sociales. [En línea]. Barcelona: Universidad de Barcelona, 15 de noviembre de 2014, Vol. XIX, nº 1098. <http://www.ub.es/geocrit/b3w-1098.htm> 
MARÍN, Martí (2001). Industrialització i migració. Burgesia i classes populars. El cas de Sabadell. Quaderns d'estudi, 17, 129-143. <http://www.raco.cat/index.php/Quaderns CELH/article/view/206199>

MASJUAN, Eduard (2000). La ecología humana en el anarquismo ibérico. Urbanismo "orgánico" o ecológico, neomalthusianismo y naturismo social. Barcelona: Icaria

MENAGES, Àngela Rosa; MONJO, Joan-Lluís (2007). Els valencians d'Algèria (18301962). Memòria i patrimoni d'una comunitat emigrada. Picanya: Edicions del Bullent.

MIRANDA, José Antonio (1993). De la tradición artesana a la especialización industrial. El calzado valenciano, 1850-1930. Revista de historia industrial, 4, 11-36.

MIRRI, Maria Teresa (1994). El proceso de formación del proletariado en un barrio industrial: el caso de Sant Martí de Provençals: integración y diferenciación social, 1862-1925. Tesis doctoral, Universitat de Barcelona, Departament d'Història Contemporània. <http://www.tdx.cat/handle/10803/405460>

MNOOKIN, Robert H. (2007). Ethnic conflicts: Flemings \& Walloons, Palestinians \& Israelis. Daedalus, 136(1), 103-119. <http://www.jstor.org/stable/20028093>

MORA, Natalia (2010). El proletariat industrial: immigració, canvi tecnològic i desigualtat social. Barcelona quaderns d'història, 16, 95-108. <http://www.raco.cat/ index.php/BCNQuadernsHistoria/article/download/226093/333188>

MORELL, Teresa (2012). Valencians a Nova York. El cas de la Marina Alta (1912-1920). La Pobla Llarga: Edicions 96.

OLIVERAS, Josep. (2013). La consolidació d'una ciutat industrial. Barcelona, 18811935. Barcelona quaderns d'història, 2013(19), 229. <http://www.raco.cat/index. php/BCNQuadernsHistoria/article/view/271954>

OLIVES, José (1969). Deterioración urbana e inmigración en un barrio del casco antiguo de Barcelona: Sant Cugat del Rec. Revista de geografia, 3(1), 40-72. <http://hdl.handle.net/10459.1/43419>

ORTELLS, Vicent (2005). La indústria ceràmica a la Plana de Castelló. Tradició històrica i mundialització actual. Treballs de la Societat Catalana de Geografia, 58, 3566. <http://www.raco.cat/index.php/treballsscgeografia/article/view/157384>

ORTUÑO, Vicent (2013). Fent les Amèriques (Ondara 1912-1920). La Pobla Llarga: Edicions 96.

OYÓN, José Luis (2008). La quiebra de la ciudad popular. Espacio urbano, inmigración y anarquismo en la Barcelona de entreguerras, 1914-1936. Ediciones del Serbal.

OYÓN, José Luis. (2009). The split of a working-class city: urban space, immigration and anarchism in inter-war Barcelona, 1914-1936. Urban History, 36(1), 86-112. <https://doi.org/10.1017/S0963926808005993>

OYÓN, José Luis (2015). Mundo obrero, inmigración y radicalismo cenetista en la Barcelona de la década de 1930. Cercles: revista d'història cultural, (18), 9-20. <http://www.raco.cat/index.php/Cercles/article/view/298909/388175>

OYÓN, José Luis; MALDONADO, Josep; GRIFUL, Eulàlia (2001). Barcelona 1930: un atlas social. Edicions UPC.

PALLARĖS, Joan (2014). Barcelona. La Sagrera-Navas. Recull gràfic 1890-1914. Barcelona: Editorial Efadós. 
PALLOL, Ruben; CARBALLO, Borja; VICENTE, Fernando (2010). Inmigración y mercado de trabajo en el Madrid de la segunda mitad del siglo XIX. Revista de Demografía Histórica, 28(1), 131-166. <http://www.adeh.org/?q=es/system/files/ Revista/I-2010/inmigracion_y_mercado_en_el_madrid_de_la_segunda_mitad_del_ siglo_xix_pallol.pdf>

PALLOL, Rubén (2011). Una ciudad de empleados: el nuevo perfil profesional de la población madrileña de 1930. En Arantza PAREJA (dir.). El capital humano en el mundo urbano: experiencias desde los padrones municipales (1850-1930) (193-218). Universidad del País Vasco/Euskal Herriko Unibertsitatea.

PIQUERAS, Andres (2005). Breu repàs històric a la migració contemporània del País Valencià i a les seues raons (amb especial atenció a la provincia de Castelló). En Andres PIQUERAS (coord.). Mediterrània migrant: les migracions al País Valencià (21-60). Castelló de la Plana: Universitat Jaume I.

PIQUERAS, Andres; LUNGU, Teodora (2007). Capital, migraciones e identidades: inmigración y sociedad en el País Valenciano: el caso de Castellón. Castelló de la Plana: Universitat Jaume I.

PUJADAS, Isabel (1982). La població de Catalunya: anàlisi espacial de les interrelacions entre els moviments migratoris i les estructures demogräfiques. Tesis doctoral, Departament d'Història Contemporània, Universitat de Barcelona, Barcelona.

PUJADAS, Joana Maria; MARÍN, Juanjo Romero; VILLAR, Conchi (2014). Propuestas metodológicas para la aplicación de HISCO en el caso de Cataluña, siglos XV-XX. Revista de Demografía Histórica, 32 (1), 181-220.

PUSCHMANN, Paul; GRÖNBERG, Per-Olof; SCHUMACHER, Reto; MATTHIJS, Koen (2014). Access to marriage and reproduction among migrants in Antwerp and Stockholm. A longitudinal approach to processes of social inclusion and exclusion, 1846-1926. The History of the family, 19(1), 29-52. <http://dx.doi.org/10. 1080/1081602X.2013.796889>

QUERALT, Mari Carme (2006). Les barraques del delta de l'Ebre, un dels habitatges populars més antics i singulars de Catalunya. Revista d'etnologia de Catalunya, 28, 96-108. <http://www.raco.cat/index.php/RevistaEtnologia/article/view/49485/633 35>

RECAÑO, Joaquín (1996). Las migraciones interiores en el área mediterránea(18601960). Universitat Autònoma de Barcelona, Centre d'Estudis Demogràfics.

SÁNCHEZ, Blanca (1995). Las causas de la emigración española 1880- 1930. Madrid: Alianza Universidad.

SILVESTRE, Javier (2007). Temporary internal migrations in Spain, 1860-1930. Social Science History, 31(4), 539-574. < https://doi.org/10.1017/S0145553200013857>

SILVESTRE, Javier (2010). Las emigraciones interiores en España: 1860-2007 (1). Historia y política: Ideas, procesos y movimientos sociales, 23, 113-134.

<https://recyt.fecyt.es/index.php/Hyp/article/view/44425/26013>

SILVESTRE, Javier; AYUDA, Maria Isabel; PINILLA, Vicente. (2015). The occupational attainment of migrants and natives in Barcelona, 1930. Economic History Review, 68 (3), 985-1015. <http://dx.doi.org/10.1111/ehr.12090> 
SOLÉ, Carlota (1981). La integración sociocultural de los inmigrantes en Cataluña. Madrid: Fundación Juan March.

TATJER, Mercedes (1972). El impacto de la industrialización en la morfología de un barrio del siglo XVIII. La evolución de la Barceloneta. Revista de Geografia, 6(1), 55-104.

TATJER, Mercedes (1973). La Barceloneta: del siglo XVIII al Plan de la Ribera. Barcelona: Ed. Saturno.

TATJER, Mercedes (1980). La inmigración en Barcelona en 1930: los andaluces en la Barceloneta, Estudios Geográficos, 41 (159), 119-144.

TATJER, Mercedes (1995). Evolució demográfica. En Jaume SOBREQUÉS (dir.). Historia de Barcelona, Vol. 7: El segle XX. De les annexions a la fi de la Guerra Civil (71-122). Barcelona: Ajuntament de Barcelona i Enciclopedia Catalana.

TATJER, Mercedes (2006). La industria en Barcelona (1832-1992). Factores de localización y cambio en las áreas fabriles: del centro histórico a la región metropolitana. Scripta Nova, 218(46), 215-231. <http://www.ub.edu/geocrit/sn/sn-218-46.htm>

TORRÓ, Lluis (1996). Al voltant dels orígens de la industrialització valenciana. En Joaquín AZAGRA (ed.); Enric MATEU (ed.); Javier VIDAL (ed.). De la sociedad tradicional a la economía moderna. Estudios de Historia Valenciana Contemporánea. Alicante: Instituto de Cultura Juan Gil-Albert.

VAN LEEUWEN, Marco H.D.; MAAS, Ineke. (2011). HISCLASS: A historical international social class scheme. Universitaire Pers Leuven.

VILLAR, Conchi (2013). Treball i gènere a la Indústria Metal-lúrgica de Barcelona (segles XIX i XX). Tesis doctoral, Universitat de Barcelona, Departament d'Història Contemporània. < http://hdl.handle.net/2445/53967>

VILLAR, Conchi (2016) The female labour force participation, a matter of supply? a matter of demand? An exercise of reconstruction in a context of poverty, Barcelona, 1930-1950. The History of the Family, 22:1, 57-81. <https://doi.org/10.1080/1081602X.2016.1168311>

VILLAR, Conchi (2018). Female Immigration in an Industrial City of Southern Europe, Barcelona 1930. Comunicación presentada en el Twelfth European Social Science History conference. Belfast, abril de 2018.

VIRUELA, Rafael (1995a). Expansión y crisis de la actividad pesquera valenciana en el siglo XIX. Investigaciones geográficas, 13, 117-134. <http://hdl.handle.net/10045/489>

VIRUELA, Rafael (1995b). Las comunidades pesqueras ante la crisis de las pesquerías y el cambio económico. Cuadernos de geografía, 57, 153-182. <http://roderic. uv.es/handle/10550/30909>

WILLIAMSON, Jeffrey G. (1990). Migrant Earnings in Britain's Cities in 1851: Testing competing views of urban labour market absorption. Journal of European Economic History, 19(1), 163-190.

<http://www.jeeh.it/articolo?urn=urn:abi:abi:RIV.JOU:1990;1.163\&ev=1>

SUAREZ, Miguel; IBARZ, Jordi (1998). La organización del trabajo portuario: los casos de Barcelona y Las Palmas de Gran Canaria (1890-1936). Parabiblos: cuadernos de Biblioteconomía y Documentación, 10, 9-18.

http://www.mdc.ulpgc.es/cdm/ref/collection/parabiblos/id/77 